\title{
Mathematical models to characterize the absorption, distribution, metabolism, and excretion (ADME) of protein therapeutics
}

\author{
Shufang Liu ${ }^{1}$, Dhaval K. Shah ${ }^{1, *}$ \\ ${ }^{1}$ Department of Pharmaceutical Sciences, School of Pharmacy and Pharmaceutical Sciences, The \\ State University of New York at Buffalo, Buffalo, NY
}

\section{*Corresponding author:}

Dhaval K. Shah, PhD

Department of Pharmaceutical Sciences

455 Pharmacy Building, School of Pharmacy and Pharmaceutical Sciences

University at Buffalo, The State University of New York

Buffalo, New York 14214-8033

Telephone: 716-645-4819

E-mail: dshah4@buffalo.edu

Number of text pages: 25

Number of tables: 2

Number of figures: 1

Number of references: 149

Number of words: 7848

Running title: PK Models for Protein Therapeutics 


\section{Abbreviations:}

Antidrug antibody (ADA)

Antibody-drug conjugates (ADCs)

Absorption, distribution, metabolism, and elimination (ADME)

Blood-brain barrier (BBB)

Blood- cerebrospinal fluid barrier (BCSFB)

Monoclonal antibodies (mAbs)

Minimal physiologically based pharmacokinetics (mPBPK)

Molecular weight (MW)

Physiologically based pharmacokinetics (PBPK)

Pharmacokinetics (PK)

Subcutaneous (SC)

Target-mediated drug disposition (TMDD)

The neonatal Fc receptor (FcRn)

Therapeutic proteins (TPs)

Transferrin receptor (TfR) 


\section{Abstract}

Therapeutic proteins (TPS) have ranked among the most important and fastest-growing classes of drugs in the clinic, yet the development of successful TPs is often limited by unsatisfactory efficacy. Understanding pharmacokinetic (PK) characteristics of TPs is key to achieving sufficient and prolonged exposure at the site-of-action, which is a prerequisite for eliciting desired pharmacological effects. PK modeling represents a powerful tool to investigate factors governing in vivo disposition of TPs. In this mini-review, we discuss many state-of-the-art models that recapitulate critical processes in each of the absorption, distribution, metabolism/catabolism, and excretion (ADME) pathways of TPs, which can be integrated into the physiologically-based pharmacokinetic (PBPK) framework. Additionally, we provide our perspectives on current opportunities and challenges for evolving the PK models to accelerate the discovery and development of safe and efficacious TPs.

\section{Significance statement}

This minireview provides an overview of mechanistic PK models developed to characterize ADME properties of therapeutic proteins (TPs), which can be used to support model-informed discovery and development of TPs. As the next-generation of TPs with diverse physicochemical properties and mechanism-of-action are being developed rapidly, there is an urgent need to better understand the determinants for the ADME of TPs and evolve existing platform PK models to facilitate successful bench-to-bedside translation of these promising drug molecules. 


\section{Introduction}

With the development of the recombinant DNA technology, therapeutic proteins (TPS) have revolutionized treatments for a multitude of diseases and steadily accounted for $50-60 \%$ of the top 10 best-selling drugs worldwide in recent years (Urquhart, 2021). Marketed TPs encompass monoclonal antibodies (mAbs), antibody fragments, enzymes, hormones, growth factors, cytokines, Fc-fusion proteins, and antibody-drug conjugates (ADCs) (Lagasse et al., 2017). MAbs represent the dominant and the fastest-growing class of TPs in the pipeline, with the $100^{\text {th }} \mathrm{mAb}$ approved just recently (Mullard, 2021). Despite their therapeutic potential, TPs have low success rates in clinical development, with only about one in ten molecules in phase 1 studies approved by the U.S. Food and Drug Administration (FDA) (Hay et al., 2014). This has been largely attributed to the failure to show significant improvement in the efficacy compared to the placebo group or existing treatments at the clinically tolerated doses of TPs (Arrowsmith, 2011). While target validation for the chosen indications is vital for the success of TPs (Morgan et al., 2012), sufficient drug exposure at the site-of-action is a prerequisite for eliciting desired pharmacodynamic (PD) effects, which underscores the importance of understanding the pharmacokinetic (PK) characteristics of TPs. Previous experience with the development of small molecule drugs has suggested that appreciation and research of drug metabolism and pharmacokinetics (DMPK) significantly reduces failures of drug candidates associated with undesired DMPK characteristics in clinical trials (Kola and Landis, 2004), and we may be witnessing such a transition in the field of TPs as well.

Because of the large size, high polarity, and high affinity of TPs, they differ substantially from traditional small molecule drugs in absorption, distribution, metabolism, and excretion (ADME) pathways (for comprehensive reviews on PK/PD properties of TPs, readers are referred to (Lobo et al., 2004; Wang et al., 2008; Vugmeyster et al., 2012; Conner et al., 2020)). Unlike many small molecules that display good gastrointestinal absorption, TPs are too large to cross the intestinal membrane and subject to proteolytic degradation in the gut. Therefore, TPs are typically administered via parenteral routes. 
Distribution of TPs is relatively restricted to the vascular and interstitial spaces, and the tissue concentration is not in rapid equilibrium with that in the plasma. While small molecule drugs are most commonly eliminated through hepatic metabolism, and renal and biliary excretion (Wienkers and Heath, 2005), TPs can be cleared via catabolism in the lysosome following nonspecific pinocytosis or receptormediated endocytosis, resulting in small peptides or amino acids that are unlikely to be pharmacologically active or toxic (Shah, 2015). Intracellular catabolism may be circumvented by the interaction between the Fc moiety of TPs and the neonatal Fc receptor (FcRn), which explains the unusually long half-life of mAbs. For TPs with a molecular weight (MW) less than around $60 \mathrm{kDa}$, renal excretion also represents an important elimination pathway (Meibohm and Zhou, 2012). Nonlinearity in the PK of TPs is not associated with small molecule transporters, metabolic enzymes, or plasma protein binding, but frequently attributed to saturable target binding or Fc receptor binding (Ferl et al., 2016).

The distinct ADME features of TPs have aroused many mathematical models to characterize the PK of these molecules. In fact, PK modeling is integral to the drug development and clinical applications of TPs, as it supports candidate selection and guides protein engineering strategies in the discovery phase, and facilitates clinical translation and optimization of dosing regimens in the clinic. In this minireview, we provide a brief overview of the PK models that can simultaneously characterize ADME processes of TPs, and elaborate on mechanistic sub-models that can characterize key distribution, elimination, and absorption processes for TPs. Additionally, we conclude with a discussion on outstanding challenges for modeling the PK of TPs.

\section{Types of PK models to characterize the ADME processes of TPs}

The most parsimonious PK model for TPs may be a classical two-compartment model with linear and/or nonlinear clearance. This model appears adequate for recapitulating PK profiles of TPs on many occasions, despite that the assumption underlying the mammillary models (i.e., the elimination of the 
drug only occurs from the central compartment) does not hold for the majority of TPs. This data-driven model mainly finds use in population PK analysis ( $\mathrm{Ng}$ et al., 2005), or in PK/PD modeling when the plasma PK is used to drive the PD model (Gibiansky and Frey, 2012).

On the other hand, physiologically-based pharmacokinetic (PBPK) models represent the most complex and mechanistic mathematical framework to characterize ADME of TPs. A typical PBPK model consists of compartments representing various organs connected via blood and lymphatic flows in an anatomical manner (Fig. 1A). Each organ is further divided into vascular, endosomal, interstitial, and cellular spaces, where TP disposition is explicitly defined using physiological processes as building blocks. PBPK models offer significant advantages over compartmental models. They yield TP concentrations and receptor occupancy in specific organs, allowing the development of reliable exposure-efficacy and exposure-toxicity relationships. The physiologic nature of PBPK models also enables robust and reliable interspecies scaling and prediction of PK, which is sometimes challenging using traditional allometric scaling, as different species have different target expression profiles, target binding, and FcRn binding affinities. Since the development of the first PBPK model for mAbs and antibody fragments by Covell et al. (Covell et al., 1986), PBPK models have evolved and expanded to incorporate up-to-date knowledge of physiology and TPs' disposition characteristics. These include molecular size-dependent distribution and elimination (Baxter et al., 1994), target turnover and binding (Baxter et al., 1994), FcRn-mediated recycling (Ferl et al., 2005; Garg and Balthasar, 2007), and interspecies scaling (Baxter et al., 1995; Shah and Betts, 2012). One should be aware that many physiological parameter values used for various species are collected from diverse resources or scaled/assumed (Shah and Betts, 2012). Boswell and colleagues published a series of work that measured organ vascular and interstitial volumes, and organ blood flow rates for rodents and monkeys, using consistent experimental techniques (Boswell et al., 2011; Boswell et al., 2014; Mandikian et al., 2018). It would be of importance to evaluate how these different physiological parameter values impact the performance of TP PBPK models. 
One way to get around the complex parameterization of a full PBPK model is to employ a minimal PBPK (mPBPK) model, in which tissues are lumped into tight (muscle, skin, adipose, and brain) or leaky (other tissues) compartments based on vasculature and permeability, and the major distribution/elimination pathways are grouped accordingly (Cao et al., 2013). This simplified model still provides physiologically meaningful parameters when only plasma data is available, and also has the potential of delineating disposition in tissues of interest, by separating out a specific tissue compartment (Chen et al., 2018).

Going forward in this manuscript, we will highlight various models describing ADME processes of TPs, mostly in the context of the PBPK framework, as these models provide the most in-depth and accurate representations of underlying mechanisms, and can be readily embedded into a mPBPK framework or linked to a compartmental model after simplification.

\section{Models to characterize distribution of TPs}

\subsection{Transcapillary transport: one-pore vs. two-pore}

While small molecules can enter tissues readily via processes like transcellular diffusion and transporter-mediated uptake, extravasation of TPs is mostly restricted to diffusion and convection through paracellular pores of vascular endothelial wall (Fig. 1B). This process can be mathematically formulated as (Bresler and Groome, 1981):

$$
\text { Flux }=J_{\text {org }} \cdot\left(1-\sigma_{V}\right) \cdot \frac{\left(C_{o r g}^{V}+C_{o r g}^{I S}\right)}{2}+P S \cdot\left(C_{o r g}^{V}-C_{o r g}^{I S}\right)
$$

Where $J_{\text {org }}$ is the organ lymph flow, $C_{\text {org }}^{V}$ and $C_{\text {org }}^{I S}$ are vascular and interstitial concentrations of a tissue, and $P S$ is the permeability-surface area product. $\sigma_{V}$ is the tissue vascular reflection coefficient, which represents the fraction of a solute that is unable to cross the pores. Typically, $\sigma_{V}$ is greater (i.e., higher resistance) for larger-size proteins (Covell et al., 1986), and tissues with less leaky vasculature (Shah and Betts, 2012). For TPs as large as mAbs (150 kDa), the transcapillary transport is considered 
almost entirely convective (Baxter et al., 1995), and thus the flux from vascular space to interstitial space can be reduced to $J_{\text {org }} \cdot\left(1-\sigma_{V}\right) \cdot C_{o r g}^{V}$. Similarly, the mass transport from interstitial fluid to lymphatics is described as $J_{\text {org }} \cdot\left(1-\sigma_{I}\right) \cdot C_{\text {org }}^{I S}$, where $\sigma_{I}$ is the lymphatic reflection coefficient. One crucial assumption underlying these equations is that the pores have a uniform size (homoporosity, or one-pore model), which contradicts the actual physiology.

The two-pore phenomenon was first noted in the 1950s (Grotte, 1956), and further elaborated and mathematically formulated by Rippe and Haraldsson (Rippe and Haraldsson, 1987; Rippe and Haraldsson, 1994). Continuous and fenestrated endothelium is assumed to contain two categories of pores, small pores (radius $r_{S}=4.44 \mathrm{~nm}$ ) and large pores (radius $r_{L}=22.85 \mathrm{~nm}$ ), and protein solutes extravasate by diffusion or convection via both types of pores (Fig. 1B). What makes the two-pore framework distinct from the one-pore model is the incorporation of isogravimetric flow $\left(J_{\text {iso }}\right)$, a circulation flow entering large pores and existing small pores, which can explain a transvascular flux of proteins even in the absence of net filtration ("isogravimetric" state). Accordingly, the actual lymph flows through these pores corrected for $J_{\text {iso }}$ are:

$$
\begin{gathered}
J_{L, \text { org }}=J_{i s o, \text { org }}+\alpha_{L} \cdot J_{\text {org }} \\
J_{S, \text { org }}=-J_{i s o, \text { org }}+\alpha_{S} \cdot J_{\text {org }}
\end{gathered}
$$

Where $J_{L, \text { org }}$ and $J_{S, \text { org }}$ are organ lymph flows through large and small pores, $\alpha_{L}$ and $\alpha_{S}$ are relative abundance of both pores, and $J_{\text {org }}$ is the net organ lymph flow. Thus, both diffusive and convective processes for protein extravasation can be characterized in the clearance terms as below:

$$
\begin{aligned}
& C L_{t p, L, o r g}=P S_{L, o r g}\left(1-\frac{C_{o r g}^{I S}}{C_{o r g}^{V}}\right) \frac{P e_{L, o r g}}{e^{P e_{L, o r g}-1}}+J_{L, o r g}\left(1-\sigma_{L}\right) \\
& C L_{t p, S, \text { org }}=P S_{S, \text { org }}\left(1-\frac{C_{\text {org }}^{I S}}{C_{\text {org }}^{V}}\right) \frac{P e_{S, o r g}}{e^{P e_{S, o r g}-1}}+J_{S, \text { org }}\left(1-\sigma_{S}\right)
\end{aligned}
$$


$C L_{t p, L, o r g}$ and $C L_{t p, S, o r g}$ are transcapillary clearances through large and small pores in an organ, $P S_{L, o r g}$ and $P S_{S, \text { org }}$ are the permeability-surface area products, and $\sigma_{L}$ and $\sigma_{S}$ are vascular reflection coefficients. Particularly, $P e_{L, \text { org }}$ and $P e_{S, \text { org }}$ are the Peclet numbers that reflect the importance of convection versus diffusion in the extravasation process, and defined as:

$$
\begin{gathered}
P e_{L, \text { org }}=\frac{J_{L, \text { org }}\left(1-\sigma_{L}\right)}{P S_{L, \text { org }}} \\
P e_{S, \text { org }}=\frac{J_{S, \text { org }}\left(1-\sigma_{S}\right)}{P S_{S, \text { org }}}
\end{gathered}
$$

The two-pore formalism has been applied in PBPK models developed for antibodies and antibody fragments since 1994 (Baxter et al., 1994). Early work typically estimated values of certain key parameters, such as $P S, P e, J_{i s o}$, and $\sigma$ (Baxter et al., 1994; Ferl et al., 2005; Davda et al., 2008), as they are difficult to measure, and can vary depending on drugs and organs. Unfortunately, these parameter estimates differ substantially between studies, and are often associated with high uncertainty and poor identifiability, restricting extensive utilization of the two-pore model. Sepp et al. mathematically derived $J_{\text {iso,org }}$ and $P S_{\text {org }}$, and found that they can be expressed as explicit linear functions of $J_{\text {org }}$. Additionally, they also reported that $P e$ could be calculated using an empirical equation for $\sigma_{v}$ (Sepp et al., 2015). Due to these derivations, their model greatly reduced the number of parameters fitted (only $J_{\text {org }}$ needed to be estimated for the two-pore extravasation), and could capture the whole-body PK of a non-binding domain antibody. In pursuit of development of a generalized PBPK model to characterize a diverse array of TPs, Li and Shah further expressed glomerular sieving coefficient (discussed later), $P S_{\text {org }}, P e$, and $\sigma$ as functions of MW, so that the two-pore PBPK model could a priori predict the PK of 8 TPs of different sizes without fitting any parameter, and facilitate a better understanding of the contribution of diffusion and convection towards protein transport across a wide range of MW (Li and Shah, 2019). 


\subsection{Special tissues}

In whole-body PBPK models, various tissues are usually treated as modules with similar kinetic processes. However, certain tissues differ significantly in terms of anatomy and physiology (e.g., solid tumor, brain, eye) and may require dedicated PK models for characterization of TP concentrations.

In solid tumors, deficient lymphatic drainage causes high interstitial hydrostatic pressure, which precludes convection of macromolecules. Meanwhile, the capillary wall tends to be more permeable than blood vessels in healthy tissues (Boucher et al., 1990). These features imply that extravasation of TPs is primarily dependent on diffusion. In addition, the solid tumor space can be viewed as a collection of Krogh cylinders, and TP distribution into the tumor can be described as:

$$
\frac{d C_{\text {extra }}}{d t}=\frac{2 P R_{\text {cap }}}{R_{\text {Krogh }}^{2}} \cdot\left(C_{P L}-\frac{C_{\text {extra }}}{\varepsilon}\right)+\frac{6 D}{R_{t}^{2}} \cdot\left(C_{\text {org }}-\frac{C_{\text {extra }}}{\varepsilon}\right)
$$

(Thurber et al., 2008; Schmidt and Wittrup, 2009; Thurber and Wittrup, 2012). The first term refers to protein permeation through the vascular capillary, and the second term indicates diffusion-driven uptake from the tumor surface that is in contact with the surrounding tissue (surface uptake), as shown in Fig. 1C. $C_{\text {extra }}, C_{P L}$, and $C_{\text {org }}$ represent TP concentrations in the tumor extracellular space, the plasma, and the surrounding tissue. $P$ is the permeability coefficient across the capillary wall, $D$ is the diffusion coefficient, $\varepsilon$ is fraction of tumor that is accessible to macromolecules, $R_{\text {cap }}$ is the capillary radius, $R_{K r o g h}$ is half the average distance between blood vessels within the tumor, and $R_{t}$ is tumor radius. It is apparent in the equation that the surface uptake pathway dominates when tumor is small and less vascularized (i.e., small $R_{t}$ ), and the TP distribution occurs almost exclusively from extravasation when tumor is larger and vasculature is well developed. Schmidt and Wittrup also derived empirical relationships between molecular size and $P, D$, and $\varepsilon$, by fitting a two-pore model of the capillary wall and a two-pore model of tumor interstitium using experimental data (Schmidt and Wittrup, 2009). These relationships not only help readily calculate tumor uptake for various TPs, but also 
provide insights into the antigen binding affinity required for prolonged retention in the tumor for different-size TPs.

In addition to extravasation into the tumor, heterogeneous intratumoral distribution is of great interest. The heterogeneity is often featured by perivascular distribution of TPs, leading to regions of antigen positive cells completely untargeted. This phenomenon is attributed to the "binding site barrier", which refers to high affinity binding to the target (and subsequent degradation) right after extravasation of the TP preventing deeper distribution into the tumor (Fujimori et al., 1990). A few model structures have been proposed to delineate heterogeneous drug distribution within a tumor, with different levels of complexities. The Krogh cylinder model in conjunction with a PBPK framework has been capable of predicting antigen bound fraction as a function of the distance from the vasculature, and evaluating strategies to overcome the binding site barrier (Cilliers et al., 2016). Shah et al. proposed a spherical tumor model that contains five circular layers with equal thickness, with adjacent layers connected by permeability surface area coefficients (Shah et al., 2009). This model can be modified to characterize the binding site barrier by incorporating target expression and binding in each tumor layer (Glassman and Balthasar, 2019). The simplest approach is to allow only a fraction of tumor antigens to be accessible for binding (Urva et al., 2010), but the associated caveats are complete loss of information about the heterogeneity, and poor generalizability of the fraction term when drug doses, binding affinities, or tumor sizes change.

Brain represents another challenging tissue to model, as it is known to have tight blood-brain barrier (BBB) and blood-cerebrospinal fluid barrier (BCSFB), and complex fluid flows in the central nervous system. A generic two-pore PBPK model in PK-Sim platform could fit antibody disposition data in mouse brain reasonably well, and the brain lymph flow and hydraulic conductivity were estimated to be extremely low (Niederalt et al., 2018). Adding a cerebrospinal fluid (CSF) flow exiting the brain that removes macromolecules can further reduce predicted brain exposures of TPs (Brinker et al., 2014; Sepp et al., 2019). Change et al. presented a higher spatial-resolution brain PBPK model that details 
paracellular transport and transcytosis through BCSFB and BBB, CSF compartmentalization (including lateral ventricle, third-fourth ventricle, cisterna magna, and subarachnoid space), and circulations of CSF and brain extracellular flow (Fig. 1D). This translational model was calibrated using rat disposition data in various brain regions, and accurately predicted brain PK of mAbs in mice, monkeys and humans (Chang et al., 2019).

As the research on eye diseases expands, ocular disposition is of more interest. The eye is characterized by delicate compartmentation, a variety of barriers, and complex fluid dynamics (Perez et al., 2013). Intravitreal dosing is the mainstream administration route in treating ocular disorders such as age-related macular degeneration and diabetic retinopathy, which requires frequent injections and causes pain. On the other hand, several anticancer mAbs and ADCs targeting diverse antigens have been shown to induce ocular toxicities following intravenous injections. As such, modeling drug exposures in the eye is valuable not only for prioritizing suitable TPs during drug development and optimization of dosing regimen, but also for evaluating ocular toxicity potential. A novel anatomical ocular compartment that contains cornea, iris-ciliary body, aqueous humor, lens, vitreous humor, retina, choroid, and sclera, embedded in a PBPK framework, has been proposed to characterize ocular disposition following intravitreal or systemic administration (Bussing and Shah, 2020), as shown in Fig. 1E. Considering that current anti-vascular endothelial growth factor (VEGF) TPs for ocular diseases include IgG, Fc-fusion, Fab, and scFv formats, the two-pore formalism is anticipated to be incorporated in the ocular compartment to better characterize the ocular absorption and disposition processes.

\section{Models to characterize catabolism and excretion of TPs}

TPs are typically eliminated by the following pathways: (i) target-mediated drug disposition, (ii) nonspecific pinocytosis/endocytosis followed by intracellular catabolism (for larger TPs) throughout the body, (iii) renal filtration (for smaller TPs) and (iv) ADA-induced clearance. In particular, FcRn-mediated salvage plays an important role in the disposition of mAbs and Fc-fusion proteins. 


\subsection{Interaction with FcRn}

FcRn is known to be expressed in vascular endothelial cells of many tissues and hematopoietic cells, and contribute to the long serum persistence of IgGs and albumin. Binding between IgGs and FcRn is $\mathrm{pH}$-dependent, with high affinity at acidic $\mathrm{pH}$ and negligible binding at physiological $\mathrm{pH}$. Following fluid phase pinocytosis, IgG binds to FcRn upon acidification of endosomes. Unbound IgG is subject to lysosomal degradation, whereas FcRn-bound IgG is returned to apical or basolateral cell surface. Once exposed to the physiological $\mathrm{pH}$ of extracellular fluid, $\lg \mathrm{G}$ is released into the systemic circulation or the interstitial fluid.

The PBPK model by Ferl et al. was one of the first to account for FcRn expression in skin and muscle, and incorporated IgG uptake into endothelia, IgG binding to FcRn, recycling of FcRn-bound IgG, and degradation of unbound IgG in the endosome (Ferl et al., 2005). The PBPK model proposed by Garg and Balthasar accounted for FcRn expression in all the tissues and characterized mAb PK in wild-type and FcRn-knockout mice (Garg and Balthasar, 2007). As shown in Fig. 1F, they assumed an equilibrium binding between $\mathrm{mAb}$ and $\mathrm{FcRn}$ in the endosomal space. Therefore, within the endosomal compartment, unbound IgG was expressed as a fraction $\left(f_{u}\right)$ of total $\lg G$, and $f_{u}$ was defined as:

$f_{u}=1-\frac{1}{2 \times C_{E n d o, o r g}^{\text {Total }}} \times\left(K_{D}+n P t_{\text {org }}+C_{E n d o, \text { org }}^{\text {Total }}-\sqrt{\left(K_{D}+n P t_{\text {org }}+C_{E n d o, o r g}^{\text {Total }}\right)^{2}-4 \times C_{E n d o, o r g}^{\text {Total }} \times n P t_{\text {org }}}\right)$.

Above, $C_{E n d o, o r g}^{\text {Total }}$ is the total endosomal lgG concentration in an organ, $n P t_{\text {org }}$ is the total $\mathrm{FcRn}$ concentration, and $K_{D}$ is the dissociation constant of the antibody for binding to FcRn. Compared to the model by Ferl, in this model the organ-specific FcRn capacity was assumed to be proportional to organ weight, and adjusted based on total FcRn amount in the body. This model estimated the fraction of FcRn-bound antibody that recycles back to the vascular space $(F R)$ to be 0.715 , and this value has been carried forward in many subsequent PBPK models. Nowadays, FcRn-mediated recycling is routinely incorporated within mAb PBPK models, with variable assumptions across models. 
Prompted by the fact that the equilibrium binding model over-predicts the improvement in antibody halflife with increasing equilibrium affinity of $\mathrm{FcRn}$ binding at $\mathrm{pH}$, Chen and Balthasar constructed a catenary FcRn binding model that describes endosomal transit process, gradual acidification of endosomes, and kinetic binding between the antibody and FcRn (Chen and Balthasar, 2012). This was justified by the fact that residence time in endosomes $(\sim 10.8 \mathrm{~min})$ is too short for the $\mathrm{mAb}-\mathrm{FcRn}$ interaction to reach equilibrium (dissociation half-life of 6-58 $\mathrm{min}$ ). In this catenary model, the vascular endosomal space is subdivided into five transit compartments with $\mathrm{pH}$ of $7.4,7.0,6.5,6.0$, and 6.0, and the transit time $(\tau)$ was determined to be 2.7 min through each compartment (Fig. 1F). FcRn was allowed to interact with $\lg \mathrm{G}$ using $\mathrm{pH}$-dependent association rates $\left(k_{o n}^{p H}\right)$ and dissociation rates $\left(k_{\text {off }}^{p H}\right)$ in each sub-compartment, and only in the last sub-compartment unbound IgG was assumed to be cleared and bound IgG was assumed to recycle. Of note, an underlying constraint between the tissue endosomal sub-compartment volume $\left(V_{\text {org }}^{E}\right)$ and uptake clearance $\left(C L_{u p}^{\text {org }}\right)$ exists in this model , to ensure endosomal volume homeostasis and FcRn and endogenous IgG steady-state:

$$
V_{\text {org }}^{E}=C L_{u p}^{\text {org }} \cdot \tau
$$

Additionally, this model employs measured tissue-specific FcRn expression (Li and Balthasar, 2018), contrary to assuming a universal FcRn concentration across tissues in prior models (Urva et al., 2010; Shah and Betts, 2012). The equilibrium binding model performed as well as the catenary model in predicting PK of normal mAbs. However, the former predicts an almost proportional increase in mAb half-life with enhanced FcRn binding, whereas the latter predicts much more modest half-life extension, which is more consistent with observations reported in the literature (Chen and Balthasar, 2012).

In prior models, FcRn concentrations are assumed to be static (either tissue-specific or universal), which make them inappropriate for characterizing PK of anti-FcRn mAbs used in treating autoimmune diseases, as FcRn density is expected to be altered under the treatment. Accordingly, on top of the catenary model, Li and Balthasar took account of FcRn turnover by supplementing an FcRn pool 
compartment (Li and Balthasar, 2019), where synthesis and degradation of FcRn can occur. This pool compartment provides the first endosomal sub-compartment with FcRn, and collects unbound and IgG-

Fc bound FcRn from the last endosomal sub-compartment, at a rate of $\frac{1}{\tau}$. Anti-FcRn mAbs are allowed to bind to FcRn through either the Fab arms or Fc region. In the last sub-compartment, Fc-bound mAb is recycled, whereas $\mathrm{mAb}-\mathrm{FcRn}$ complexes linked via the Fab domain are either degraded or recycled directly to the first sub-compartment. Such model scheme allows characterization of FcRn depletion in the presence of FcRn inhibitors.

There is also a growing interest in the role of hematopoietic cells in mAb PK (Challa et al., 2019; Malik and Edginton, 2020), as FcRn is expressed in these cells (Vidarsson et al., 2006; Latvala et al., 2017), and hematopoietic cells exist ubiquitously in the body (Yu et al., 2016). Experiments involving wild-type and hematopoietic cell-specific FcRn knockout mice have shown that endothelial and hematopoietic cells almost contributed equally to FcRn-mediated salvage (Akilesh et al., 2007; Montoyo et al., 2009; Richter et al., 2018). Correspondingly, the model mentioned above also considers mAb-FcRn interactions in endosomal space associated with hematopoietic cells, which are assumed to reside within the lymph, tissue interstitial space, and plasma (Li and Balthasar, 2019). However, widespread validation of such model remains unaccomplished.

\subsection{Target-mediated drug disposition (TMDD)}

Target-mediated drug disposition (TMDD), a term coined by Levy (Levy, 1994), refers to situations where high-affinity binding to the target impacts the PK characteristics of the drug. TMDD applies to the majority of TPs, as this class of drugs is designed to have high affinity and specificity for their targets. However, its impact on the PK is only noticeable at lower TP concentrations when this pathway is not saturated. TMDD modeling has a history of about 20 years, and many seminal works have been done to establish the mechanistic framework, evaluate the identifiability of model parameters, simplify the model equations, and modify the model to characterize novel molecules. Interested readers are 
referred to (Mager and Krzyzanski, 2005; Gibiansky et al., 2008; Marathe et al., 2009; Gibiansky and Gibiansky, 2014; Lavezzi et al., 2018; Peletier and Gabrielsson, 2018) for detailed education on this topic. Only a few TMDD models will be highlighted below.

A full, generic TMDD model was proposed by Mager and Jusko (Mager and Jusko, 2001). The model assumes that drug in the central compartment $\left(C_{p}\right)$ can distribute into the peripheral compartment $\left(D_{T}\right)$, be cleared in its free form (via the elimination rate $k_{e l}$ ), or bind (rate constant, $k_{o n}$ ) to the free target $(R)$ to form the drug-receptor complex $(R C) . R$ is produced (via the synthesis rate, $k_{\text {syn }}$ ) and eliminated (via the degradation rate, $\left.k_{d e g}\right)$ in the central compartment, whereas $R C$ may undergo dissociation $\left(k_{o f f}\right)$ or internalization $\left(k_{\text {int }}\right)$. For soluble targets, $k_{\text {int }}$ is usually close to $k_{e l}$ of the free drug. For membranebound targets, $k_{\text {int }}$ is often similar to $k_{d e g}$ of the free receptor, and when this holds, the total receptor concentration $\left(R_{\text {tot }}\right.$, i.e. $\left.R+R C\right)$ is constant, which eliminates the need to mathematically define temporal changes in $R_{\text {tot }}$. Several approximations of the full TMDD model can be implemented to avoid estimating practically unidentifiable parameters such as $k_{\text {on }}$ and $k_{o f f}$, and to make the equations less stiff. For example, when $k_{o n}, k_{o f f}$, and $k_{\text {int }}$ are much faster than the remaining processes, it can be assumed that the free drug, the free receptor, and complex are at quasi-steady-state, with $R C=\frac{R_{t o t} \cdot C_{p}}{K_{S S}+C_{p}}$ at all times, where $K_{S S}$ represents $\frac{k_{\text {off }}+k_{\text {int }}}{k_{\text {on }}}$ (Gibiansky et al., 2008). If $k_{\text {int }}$ is much smaller than $k_{o f f}$, the assumption of quasi-equilibrium becomes valid, where $R C=\frac{R_{t o t} \cdot C_{p}}{K_{D}+C_{p}}$, with $K_{D}$ being $\frac{k_{\text {off }}}{k_{\text {on }}}$ (Mager and Krzyzanski, 2005). Furthermore, if $R \ll C_{p}$, both quasi-steady-state and quasi-equilibrium models can be reduced to Michaelis-Menten approximation (Gibiansky et al., 2008).

PBPK models usually adopt the full, quasi-steady-state, or quasi-equilibrium TMDD component in the tumor compartment (Urva et al., 2010; Shah and Betts, 2012; Cao and Jusko, 2014), using receptor and drug concentrations at the site-of-action instead of the central compartment (Fig. 1G). Parameters such as $R_{\text {tot }}, K_{D}, k_{\text {on }}, k_{\text {off }}$, or even $k_{\text {int }}$ to operate these models could be obtained from in vitro 
measurements. Other physiologically relevant issues also need to be considered by these models, such as tumor antigen accessibility (discussed in "Distribution models" section) and antigen shedding. Many membrane-bound targets are known to shed the ectodomains or have a soluble form in the body (Kuang et al., 2010). This circulating pool competes with the cell-surface counterpart for drug binding, and alters disposition and efficacy of the TP. A mPBPK-TMDD model incorporating the target shedding mechanism of human epidermal growth factor receptor 2 (HER2) has systematically evaluated the effects of target shedding kinetics, soluble target turnover, and affinity difference between cell-surface HER2 and shed HER2, on plasma PK of trastuzumab (an anti-HER2 antibody), as well as receptor occupancy of membrane-bound HER2 (Li et al., 2014). Such TMDD model with target shedding was further modified and incorporated into a population PBPK framework to demonstrate the concentration of shed HER2 ectodomain as one of the key factors that contribute towards inter-individual variability in trastuzumab PK (Malik et al., 2017).

\subsection{Renal elimination}

Kidney contributes to both catabolism and excretion of TPs. Renal excretion is a highly size-dependent process, and therefore is an important determinant of PK differences observed for TPs across a wide MW range. The molecular size cut-off for glomerular filtration is approximately $60 \mathrm{kD}$, and an inverse sigmoidal relationship between glomerular sieving coefficient (GSC) and MW has been demonstrated (Haraldsson et al., 2008). The size-selectivity makes the renal filtration process fit well with the twopore model, where GSCs can be expressed as empirical functions of MW (Li and Shah, 2019; Sepp et al., 2019). A pathway analysis reveals that lysosomal catabolism dominates the elimination of TPs with MW greater than $100 \mathrm{kD}$, and TPs less than $100 \mathrm{kDa}$ are mostly eliminated via renal filtration (Li and Shah, 2019). In addition to size, other TP-specific factors also play a role in glomerular filtration. A positive correlation between GSC and molecular charge was also observed, which is attributed to the negatively charged glycocalyx of the filtration barrier (Haraldsson et al., 2008). A recent study reveals that renal filtration is higher for one-armed (nonbranched) IgGs and IgGs with a more flexible hinge 
region (Rafidi et al., 2021). More quantitative data on systemic and kidney PK of TPs are needed to incorporate factors such as charge, shape, and rigidity as covariates in PK models. Similar to other organs, renal endothelial cells can take up TPs for lysosomal degradation. Additionally, renal catabolism can occur via reabsorption into endocytic vesicles of proximal tubule cells following glomerular filtration, or by peritubular extraction of TPs from postglomerular capillaries (Meibohm and Zhou, 2012), as shown in Fig. 1H. However, these catabolism mechanisms have not been explicitly accounted for in most current models.

\subsection{Immunogenicity}

TPs with antigenic components, such as foreign sequences and impurities, can induce immunogenicity and antidrug antibody (ADA) formation. Although in rare cases, ADAs serve as a storage depot that sustains TP exposures (Wang et al., 2008), they often compromise drug PK to varying degrees, depending on ADA titer, kinetics, and types (neutralizing or non-neutralizing).

Empirical models with time-varying PK parameters have been used to study the impact of immunogenicity on PK of TPs. For example, a parameter termed change in clearance time $(\alpha)$ was included in a two-compartment TMDD model, which allows the linear clearance to suddenly change at time $\alpha$, presumably due to ADA formation (Kathman et al., 2016). It was found that the derived $\alpha$ can be much earlier than the time when ADA is detected in bioassays, and thus is helpful in identifying falsenegative subjects. Certain more mechanistic models introduce a compartment representing ADA depot that is activated by repeated dosing of TPs, and after some transit time, ADAs are available in the central compartment to bind to TPs and get eliminated (Chen et al., 2013; Perez Ruixo et al., 2013). The dissociation rate of ADAs binding to TPs can decay over time to reflect affinity maturation (Chen et al., 2013).

These models are useful to determine the onset and magnitude of influence of ADA on TP disposition, but cannot project immunogenicity based on in vitro and preclinical data. To aid the immunogenicity risk 
assessment during drug development, Chen et al. proposed a mechanistic, multiscale, prototype framework that integrates subcellular, cellular, and whole-body level models (Chen et al., 2014a; Chen et al., 2014b). The subcellular model focuses on antigen presentation processes, including activation of dendritic cells by endotoxin existent in TP formulations, internalization of the antigenic TP, degradation of the TP into T cell epitope peptides, binding between peptides and major histocompatibility complex class II (MHC-II) molecules, and presentation of T-epitope-MHC complexes on dendritic cell membrane. The cellular model further recapitulates activation, proliferation, and differentiation of T helper cells and $B$ cells, which ultimately results in the secretion of ADAs from plasma cells. Total 17 sub-groups of $B$ cells and derived ADAs are assumed with incremental binding affinities to the antigenic TP, so that the affinity maturation can be captured. The differential equation based subcellular and cellular models are readily integrated with an extended two-compartment model to describe in vivo disposition of ADAs and the TP. Modeling the impact of immunogenicity on PK is achieved by adding the following two components to the clearance of TP: (i) rapid elimination of ADA-TP immune complex, and (ii) internalization of TP following B cell receptor binding. Of note, such mechanistic modeling allows for incorporating drug-specific, product-specific, and patient-specific characteristics, and can generate predictions of immunogenicity incidence and its influence on PK of TPs in a given population.

\section{Models to characterize TP absorption}

Due to the presence of proteolytic enzymes in the gastrointestinal tract, TPs are frequently administered via parenteral routes, such as intravenous, subcutaneous (SC), and intramuscular (IM) delivery. SC administration has been approved for the delivery of many TPS, as it is the most convenient route for chronic treatments, and enables drug delivery for prolonged periods of time (McDonald et al., 2010). SC dosing refers to injections into the hypodermis (interstitial space), from where TPs can gain access to the systemic circulation, via diffusion through blood capillaries (for TPs with $\mathrm{MW}<16 \mathrm{Kd}$ ) or convection through the lymphatic vessels (for TPs with MW>16 kD) that drain into 
the blood. For molecular modalities with Fc, FcRn-mediated transcytosis serves as an important pathway for the SC absorption (Deng et al., 2012; Richter and Jacobsen, 2014).

To model the absorption of TPs, an absorption site compartment can be linked to the central/plasma compartment via some absorption rate constants; the bioavailability can be explicitly expressed as $F$, or reflected in a first-order degradation process from the SC site. Readers are referred to the review (Kagan, 2014) that describes applications of such empirical and semi-mechanistic models in characterizing SC absorption of diverse TPs, and physiological interpretations of relevant parameters. In the PBPK framework, the SC site is often considered as a typical tissue compartment with vascular, endosomal, interstitial (i.e., the injection site), and cellular space. An extra clearance term is allowed either in the interstitial space or in the local lymphatic capillary, to represent pre-systemic catabolism that occurs outside vascular endothelia, as shown in Fig. 1 ( (Porter and Charman, 2000).

Many physiological factors such as FcRn expression, lymphatic vessel density and lymph flow rates, extracellular matrix (ECM), and injection sites, together with physicochemical properties of TPs such as MW, charge, aggregation potential, and immunogenicity, are known to influence PK following SC administration (Sanchez-Felix et al., 2020). Mechanistic models have been utilized to mathematically describe the interplay of these factors and to investigate their impacts on the extent and rate of SC absorption. Sensitivity analysis done in various models has revealed that $T_{\max }$ is most sensitive to lymphatic flow rate, whereas bioavailability is significantly impacted by lymphatic transit time, degradation during lymphatic transport, FcRn expression, and FcRn binding affinity (Zhao et al., 2013; Kagan, 2014). To mechanistically understand the effect of molecular size on SC absorption, a two-pore formalism can be applied in the SC site (Ibrahim et al., 2012; Gill et al., 2016; Hu and D'Argenio, 2020; Li et al., 2021), as discussed in the "Distribution models" section. Pathway analysis using such two-pore models suggests that percentage of pre-systemic degradation increased with increasing MW of proteins, with the exception of mAbs due to FcRn-mediated protection, and that the fraction absorbed through lymphatic transportation becomes more prominent for larger-size TPs (Gill et al., 2016; Li et al., 
2021). Positive charge patches on TPs are believed to interact with abundant hyaluronic acid, the highly negatively charged polysaccharides in SC space, which hinders the movement of molecules in the interstitium (Reddy et al., 2006; Mach et al., 2011). Correspondingly, proteins with higher pls showed delayed $T_{\max }$ in lymph and reduced SC bioavailability (Reddy et al., 2006; Zheng et al., 2012). A two-pore PBPK model that intended to a priori predict human plasma PK of different-size TPs following SC failed to see any correlation between prediction accuracy of $C_{\max }$ or $T_{\max }$ and TP pls (Gill et al., 2016). In contrast, another two-pore PBPK model that allowed flexibility in SC lymphatic capillary clearance for 12 antibodies found a positive correlation between the parameter estimates and the positive charge in CDRs (Hu and D'Argenio, 2020). Richer data from more TPs and a wider range of $\mathrm{pl} /$ charge are needed to validate and refine such correlations derived from the PBPK models.

All the above-mentioned models can capture experimental data reasonably well, but their interspecies translatability and physiological relevance remain questionable. It is well recognized that prediction of SC absorption in humans based on data from preclinical species is very difficult (Collins et al., 2020), which is largely attributed to interspecies differences in skin physiology (e.g., panniculus carnosus muscle is present in lower species but absent in humans) (Richter and Jacobsen, 2014), FcRn interactions (Ober et al., 2001), and relative contribution of lymphatics to the absorption (e.g., lymphatic absorption is important to SC bioavailability in sheep but less so in rodents) (Porter et al., 2001; Kagan et al., 2007). To our knowledge, traditional empirical models in conjugation with allometric scaling and mechanistic PBPK models do not seem to be capable of taking into account these complexities and robustly projecting bioavailability across species. In addition, it has been suggested that FcRn-mediated protection of mAbs in hematopoietic cells is important to SC bioavailability, as the bioavailability was greatly compromised when FcRn was absent only in hematopoietic cells (Richter et al., 2018). The importance of this absorption mechanism needs to be thoroughly evaluated via modeling approaches.

Despite the predominant role of SC dosing in clinical TP therapies, other administration routes of TPS are gaining attention. Among them, non-invasive pulmonary delivery is experiencing renewed interest, 
in view of the outbreak of COVID-19. Two marketed inhaled TPs, rhDNase I (Pulmozyme®) and insulin (Afrezza®), represent locally and systemically acting biologics via pulmonary entry, respectively. More than 25 inhaled TPs are being evaluated in clinical trials, targeting cystic fibrosis, asthma, and respiratory viral infections including COVID-19 (Liang et al., 2020). Pulmonary delivery takes advantage of the large surface area, extensive vasculature, relatively low proteolytic enzyme activity, and high permeability in the lung (Chung et al., 2012), with the potential to achieve rapid absorption for systemic delivery (Patton and Byron, 2007), and high local concentrations for topical therapy. Meanwhile, it faces challenges such as branching lung structures as barriers for deposition, limited fluid volume for particle dissolution (Patton et al., 2010), and rapid mucociliary and macrophage clearance. Therefore, mathematical lung sub-models that incorporate salient anatomical features, spatial distribution of FcRn, fluid dynamics, protein transportation kinetics, and mucociliary clearance would be helpful in quantitative understanding of mechanisms underlying pulmonary absorption, and guiding strategies to optimize TPs for inhalation. A multicompartment lung PBPK model originally intended for small molecules can serve as a starting template (Gaohua et al., 2015), and be further expanded to depict macromolecule-relevant processes.

\section{Opportunities and Challenges}

All the PK models for TPs described above have some advantages and disadvantages associated with them, which have been summarized in Table 1. Depending on their applicability, different models are frequently used in mechanistic preclinical studies and clinical settings to expedite drug discovery and development process (Glassman and Balthasar, 2019; Gibbs et al., 2020). The ultimate goal of investigating and modeling PK of TPs is to translate preclinical findings into humans, and facilitate firstin-human $(\mathrm{FIH})$ dose selection and optimization of clinical dosing regimens. There is currently no consensus on the best way for interspecies scaling of TPs' PK (Germovsek et al., 2021). Nonetheless, multiple attempts have been made to validate the capability of PK models to predict human PK from preclinical species, or to extrapolate from human adults to pediatric populations, as listed in Table 2. 
Although detailed discussion of this topic is beyond the scope of this mini-review, cross-species and cross-population prediction of TPs' PK is a promising and rapidly growing area. Going forward, more work needs to be done to reveal physiological differences between species or populations that may impact ADME of TPs, and to demonstrate general applicability of such PK models for a diverse array of TPs under different pathological conditions. In this section, we have further discussed additional opportunities and challenges that PK scientists may face while developing mathematical models to characterize ADME of TPs.

\subsection{Inter-antibody differences in PK}

The most prominent feature that distinguishes diverse TPs is the MW range (3.5 kDa to $150 \mathrm{kDa})$, and the size-dependent ADME mechanisms have been decently characterized using two-pore models. Nonetheless, mAbs with MW of around $150 \mathrm{kDa}$ can still display very distinct PK profiles, even in cases where FcRn affinities are similar and TMDD is absent. Other key factors that are known to govern ADME properties of mAbs include charge, glycosylation, and shape, and some emerging models have attempted to address their influences on mAb PK.

Chen and Balthasar suggested two coefficients, $F 1$ and $F 2$, that can be applied to modify the endosomal uptake clearance $\left(F 1 \cdot C L_{u p}\right)$ and transcapillary convection $\left(F 2 \cdot\left(1-\sigma_{v}\right)\right)$, respectively, to account for inter-antibody variability in PK (Chen and Balthasar, 2012; Glassman et al., 2015). Using a similar yet augmented approach, Hu and D'Argenio applied four mAb-specific parameters in a PBPK model that represent antibody variabilities in the pinocytosis rate $\left(S_{\text {pino }}\right)$, diffusive/convective transport rates $\left(S_{\text {diff-conv }}\right)$, and lymphatic capillary uptake rate $\left(S_{L y m U p t}^{S C}\right)$ and pre-systemic clearance $\left(C L_{L y m U p t}^{S C}\right)$ following SC dosing, to individually fit IV and SC PK data of many mAbs in the training dataset (Hu and D'Argenio, 2020). It was found that parameter estimates of both $S_{\text {pino }}$ and $C L_{L y m U p t}^{S C}$ positively correlated with positive charges of CDR vicinity (PPC), consistent with the observations that increased positive charges of mAbs lead to enhanced cellular uptake and lower bioavailability (Bumbaca Yadav et 
al., 2015; Datta-Mannan et al., 2015). When these two relationships based on PPC were incorporated in the model, they were able to a priori predict SC PK of 3 out of $4 \mathrm{mAbs}$ in the test dataset. Jones et al. also modeled the impact of molecular charge on mAb PK, using a somewhat different approach (Jones et al., 2019). Contrary to the predictor used in the model by Hu and D'Argenio, PPC, which is theoretically calculated, this work used the data from affinity-capture self-interaction nanoparticle spectroscopy (AC-SINS), an in vitro assay that detects nonspecific charge-based interactions, as a covariate in the PBPK model. Instead of moderating the pinocytosis rate, the authors involved nonspecific binding between mAbs and cell membrane sites, and internalization of the membranebound complex via pinocytosis. The nonspecific binding equilibrium constant was expressed as a function of AC-SINS scores, whereby greater self-association leading to higher binding affinity. After model calibration, mAb PK in mice and humans was predicted relatively well.

Modeling approaches incorporating the impact of glycosylation on mAb PK are less explored. This is in part due to inconsistent observations of the effect of high mannose (Kanda et al., 2007; Yu et al., 2012), hybrid type glycans (Kanda et al., 2007; Falck et al., 2021), and galactosylation (Wright et al., 2000;

Falck et al., 2021) on clearance. As glycoengineering of TPs gain more popularity, it can be expected that glycosylation will be an important covariate in PK models. As has been discussed in the "Renal elimination" section, more data are needed to substantiate the relationship between molecular shape, charge, or rigidity and kidney elimination. Ultimately, a platform PBPK model incorporating physicochemical characteristics of TPs holds promise for predicting PK based on in silico and in vitro properties, and guiding protein engineering strategies to achieve maximum and specific exposure at the site-of-action.

\subsection{Modeling next-generation TPs}

Innovative protein engineering technologies have paved the way for the generation of an array of novel TPs, which often possess unique physicochemical properties and mechanisms-of-action. Mechanistic models need to be evolved to understand determinants controlling their PK/PD, and to aid in rational 
design of these next-generation modalities. Previous models may work well in capturing existent data, but novel molecules and unusual scenarios often require reexamination of model assumptions and refinement of model structures. Based on the types of modeling efforts required to elucidate the ADME mechanisms, these next-generation TPs can be roughly categorized into two non-exclusive groups.

The first group of TPs necessitate highly mechanistic cellular models to characterize intracellular processing, due to endosomal-environment switch mechanisms, or their intracellular-delivery nature. The well-known concept of "recycling antibodies" has been applied to IL-6R, IL-6, and PCSK 9, where antibodies bind tightly to the target extracellularly at $\mathrm{pH} 7.4$ or with low calcium ion concentration, and dissociate rapidly from the target in endosomes where $\mathrm{pH}$ is low or calcium ion is concentrated. These "catch-and-release" mAbs are expected to improve neutralization of soluble targets, and detailed modeling work has identified target turnover and $\mathrm{pH}$-dependent binding affinity difference that maximize target clearance (Glassman and Balthasar, 2016a; Yang et al., 2017; Jones et al., 2020). The acidswitched binding is also of interest for membrane-bound targets (Kang et al., 2019), but relevant modeling analysis is scarce. ADCs are a class of drugs for which complex ADME properties have been extensively evaluated in PKPD models. Multiscale models have been developed to characterize systemic disposition and intracellular processing of the intact ADC, the antibody moiety, and the free drug (Maass et al., 2016; Khot et al., 2017; Singh and Shah, 2017a; Singh and Shah, 2017b; Singh et al., 2020). In recent years, biparatopic ADCs that recognize two non-overlapping epitopes of the same target have gained much interest. Such constructs are believed to promote receptor clustering, inhibit receptor recycling and promote lysosomal trafficking of the receptor and ADCs, thereby increasing cytotoxic drug release, as exemplified by biparatopic ADCs targeting HER2 (Li et al., 2016), MET (DaSilva et al., 2021), and EGFR (Fan et al., 2021). A mechanistic model can provide a quantitative understanding of the extent to which intracellular trafficking is altered, the resultant drug exposure improvement, and the long-term impact of receptor downregulation caused by clustering. 
The second type of next-generation TPs utilize previously less understood receptor-mediated disposition pathways. For example, exploiting transferrin receptor (TfR)-mediated transcytosis has been recognized as a strategy to enhance drug delivery across the BBB, as demonstrated using ADCs or bispecific mAbs targeting both TfR and therapeutic targets (Friden et al., 1991). Intriguingly, higher antibody exposure in the brain is observed when TfR engagement is monovalent or has only intermediate affinity (Yu et al., 2011; Niewoehner et al., 2014; Chang et al., 2021b), which ensures both sufficient TfR binding at the luminal side and efficient release to the abluminal side. Empirical and semimechanistic PKPD models have been explored to predict the optimal TfR affinity that maximizes brain exposure, as well as the impact on efficacy and safety (Gadkar et al., 2016; Kanodia et al., 2016). However, the influence of TfR binding valency has not been characterized, and translation of mouse and monkey models to human remains to be validated. Fc gamma receptors (FcyR)-mediated elimination represents another pathway that can play a role in TP disposition. FcyRs are known to be important in immune responses to mAbs, but their role in mAb PK is less defined. Although experiments with FcyR knockout mice suggested a minor role of FcyR in PK of a typical IgG1 molecule (Abuqayyas and Balthasar, 2012), for those TPs that can form large, high-order immune complexes with soluble ligands (Mortensen et al., 2012; Kasturirangan et al., 2017), or that have significant ADCC resulting in target cell depletion (Uchida et al., 2004), interaction with FcyRs may impact TP disposition. However, a systematic modeling analysis of this pathway is currently lacking. Another modality that falls in this category is albumin-fusion or albumin binding domain (ABD)-conjugated TPs, which leverages pH-dependent albumin-FcRn interactions to achieve half-life extension. This strategy has been applied to IgA (Meyer et al., 2016), single-chain diabodies (Stork et al., 2007), scFv (Sanches et al., 2020), domain antibodies (Goodall et al., 2015), and affibodies (Andersen et al., 2011). A PBPK framework with the two-pore formalism has been demonstrated to well characterize PK of albumin, ABDs, and ABD-conjugated diabody (Sepp et al., 2019; Sepp et al., 2020). However, a more extensive evaluation of how the size of the unmodified TP and the size of the albumin-binding modality/albumin variants impact the half-life of TPs is still needed. 


\section{Conclusions}

Mathematical and mechanistic PK models are crucial for the development of exposure-efficacy and exposure-toxicity relationships for TPs in preclinical species and humans. Here we underscore the potential of PBPK modeling in characterizing unique ADME properties of TPs, and demonstrate a diverse array of models with variable assumptions in describing transcapillary transport, tissue distribution, FcRn-mediated recycling, TMDD, renal elimination, and absorption. These models shed light on critical determinants influencing TPs' exposures in circulation or at the site-of-action, and target engagement. We also highlight the emerging needs to integrate physicochemical properties of TPs in PK models to explain intermolecular PK variability, and to elucidate novel disposition mechanisms of next-generation TPs using novel models. It is anticipated that the advanced PK models will facilitate triaging of TP candidates and optimization of molecular design. These quantitative tools can also facilitate model-informed discovery and development of biotherapeutics. 


\section{Acknowledgements}

DKS is supported by National Institute of General Medical Sciences grant [GM114179], the Center of Protein Therapeutics at the University at Buffalo, National Institute of Allergy and Infectious Diseases grant [Al138195], and National Cancer Institute grants [R01CA246785 and R01CA256928].

\section{Financial Disclosure Statement}

No author has an actual or perceived conflict of interest with the contents of this article.

\section{Authorship contributions}

Wrote or contributed to the writing of the manuscript: Shufang Liu and Dhaval K. Shah 


\section{References}

Abuqayyas $L$ and Balthasar JP (2012) Application of knockout mouse models to investigate the influence of FcgammaR on the tissue distribution and elimination of $8 \mathrm{C} 2$, a murine $\lg \mathrm{G} 1$ monoclonal antibody. Int $J$ Pharm 439:8-16.

Akilesh S, Christianson GJ, Roopenian DC, and Shaw AS (2007) Neonatal FcR expression in bone marrow-derived cells functions to protect serum IgG from catabolism. J Immunol 179:4580-4588.

Andersen JT, Pehrson R, Tolmachev V, Daba MB, Abrahmsen L, and Ekblad C (2011) Extending halflife by indirect targeting of the neonatal $F c$ receptor $(F c R n)$ using a minimal albumin binding domain. J Biol Chem 286:5234-5241.

Arrowsmith J (2011) Trial watch: phase III and submission failures: 2007-2010. Nat Rev Drug Discov 10:87.

Baxter LT, Zhu H, Mackensen DG, Butler WF, and Jain RK (1995) Biodistribution of monoclonal antibodies: scale-up from mouse to human using a physiologically based pharmacokinetic model. Cancer Res 55:4611-4622.

Baxter LT, Zhu H, Mackensen DG, and Jain RK (1994) Physiologically based pharmacokinetic model for specific and nonspecific monoclonal antibodies and fragments in normal tissues and human tumor xenografts in nude mice. Cancer Res 54:1517-1528.

Boswell CA, Ferl GZ, Mundo EE, Bumbaca D, Schweiger MG, Theil FP, Fielder PJ, and Khawli LA (2011) Effects of anti-VEGF on predicted antibody biodistribution: roles of vascular volume, interstitial volume, and blood flow. PLoS One 6:e17874.

Boswell CA, Mundo EE, Ulufatu S, Bumbaca D, Cahaya HS, Majidy N, Van Hoy M, Schweiger MG, Fielder PJ, Prabhu S, and Khawli LA (2014) Comparative physiology of mice and rats: radiometric measurement of vascular parameters in rodent tissues. Mol Pharm 11:1591-1598.

Boucher Y, Baxter LT, and Jain RK (1990) Interstitial pressure gradients in tissue-isolated and subcutaneous tumors: implications for therapy. Cancer Res 50:4478-4484.

Bresler EH and Groome LJ (1981) On equations for combined convective and diffusive transport of neutral solute across porous membranes. Am J Physiol 241:F469-476.

Brinker T, Stopa E, Morrison J, and Klinge P (2014) A new look at cerebrospinal fluid circulation. Fluids Barriers CNS 11:10.

Bumbaca Yadav D, Sharma VK, Boswell CA, Hotzel I, Tesar D, Shang Y, Ying Y, Fischer SK, Grogan JL, Chiang EY, Urban K, Ulufatu S, Khawli LA, Prabhu S, Joseph S, and Kelley RF (2015) Evaluating the Use of Antibody Variable Region (Fv) Charge as a Risk Assessment Tool for Predicting Typical Cynomolgus Monkey Pharmacokinetics. J Biol Chem 290:29732-29741.

Bussing D and Shah D (2020) Development of a physiologically-based pharmacokinetic model for ocular disposition of monoclonal antibodies in rabbits. $J$ Pharmacokinet Pharmacodyn 47:597612.

Cao Y, Balthasar JP, and Jusko WJ (2013) Second-generation minimal physiologically-based pharmacokinetic model for monoclonal antibodies. J Pharmacokinet Pharmacodyn 40:597-607.

Cao $Y$ and Jusko WJ (2014) Incorporating target-mediated drug disposition in a minimal physiologically-based pharmacokinetic model for monoclonal antibodies. J Pharmacokinet Pharmacodyn 41:375-387.

Challa DK, Wang X, Montoyo HP, Velmurugan R, Ober RJ, and Ward ES (2019) Neonatal Fc receptor expression in macrophages is indispensable for lgG homeostasis. MAbs 11:848-860.

Chang HP, Shakhnovich V, Frymoyer A, Funk RS, Becker ML, Park KT, and Shah DK (2021a) A population physiologically-based pharmacokinetic model to characterize antibody disposition in pediatrics and evaluation of the model using infliximab. British Journal of Clinical Pharmacology.

Chang HY, Wu S, Li Y, Zhang W, Burrell M, Webster Cl, and Shah DK (2021b) Brain pharmacokinetics of anti-transferrin receptor antibody affinity variants in rats determined using microdialysis. MAbs 13:1874121. 
Chang HY, Wu S, Meno-Tetang G, and Shah DK (2019) A translational platform PBPK model for antibody disposition in the brain. $J$ Pharmacokinet Pharmacodyn 46:319-338.

Chen X, Hickling T, Kraynov E, Kuang B, Parng C, and Vicini P (2013) A mathematical model of the effect of immunogenicity on therapeutic protein pharmacokinetics. AAPS J 15:1141-1154.

Chen X, Hickling TP, and Vicini P (2014a) A mechanistic, multiscale mathematical model of immunogenicity for therapeutic proteins: part 1-theoretical model. CPT Pharmacometrics Syst Pharmacol 3:e133.

Chen X, Hickling TP, and Vicini P (2014b) A mechanistic, multiscale mathematical model of immunogenicity for therapeutic proteins: part 2-model applications. CPT Pharmacometrics Syst Pharmacol 3:e134.

Chen X, Jiang X, Doddareddy R, Geist B, Mclntosh T, Jusko WJ, Zhou H, and Wang W (2018) Development and Translational Application of a Minimal Physiologically Based Pharmacokinetic Model for a Monoclonal Antibody against Interleukin 23 (IL-23) in IL-23-Induced Psoriasis-Like Mice. J Pharmacol Exp Ther 365:140-155.

Chen $Y$ and Balthasar JP (2012) Evaluation of a catenary PBPK model for predicting the in vivo disposition of mAbs engineered for high-affinity binding to FcRn. AAPS J 14:850-859.

Chung SW, Hil-lal TA, and Byun Y (2012) Strategies for non-invasive delivery of biologics. J Drug Target 20:481-501.

Cilliers C, Guo H, Liao J, Christodolu N, and Thurber GM (2016) Multiscale Modeling of Antibody-Drug Conjugates: Connecting Tissue and Cellular Distribution to Whole Animal Pharmacokinetics and Potential Implications for Efficacy. AAPS J 18:1117-1130.

Collins DS, Sanchez-Felix M, Badkar AV, and Mrsny R (2020) Accelerating the development of novel technologies and tools for the subcutaneous delivery of biotherapeutics. J Control Release 321:475-482.

Conner KP, Devanaboyina SC, Thomas VA, and Rock DA (2020) The biodistribution of therapeutic proteins: Mechanism, implications for pharmacokinetics, and methods of evaluation. Pharmacol Ther 212:107574.

Covell DG, Barbet J, Holton OD, Black CD, Parker RJ, and Weinstein JN (1986) Pharmacokinetics of monoclonal immunoglobulin G1, F(ab')2, and Fab' in mice. Cancer Res 46:3969-3978.

DaSilva JO, Yang K, Surriga O, Nittoli T, Kunz A, Franklin MC, Delfino FJ, Mao S, Zhao F, Giurleo JT, Kelly MP, Makonnen S, Hickey C, Krueger P, Foster R, Chen Z, Retter MW, Slim R, Young TM, Olson WC, Thurston G, and Daly C (2021) A Biparatopic Antibody-Drug Conjugate to Treat MET-Expressing Cancers, Including Those that Are Unresponsive to MET Pathway Blockade. Mol Cancer Ther.

Datta-Mannan A, Thangaraju A, Leung D, Tang Y, Witcher DR, Lu J, and Wroblewski VJ (2015) Balancing charge in the complementarity-determining regions of humanized mAbs without affecting $\mathrm{pl}$ reduces non-specific binding and improves the pharmacokinetics. MAbs 7:483-493.

Davda JP, Jain M, Batra SK, Gwilt PR, and Robinson DH (2008) A physiologically based pharmacokinetic (PBPK) model to characterize and predict the disposition of monoclonal antibody CC49 and its single chain Fv constructs. Int Immunopharmacol 8:401-413.

Deng R, Meng YG, Hoyte K, Lutman J, Lu Y, lyer S, DeForge LE, Theil FP, Fielder PJ, and Prabhu S (2012) Subcutaneous bioavailability of therapeutic antibodies as a function of FcRn binding affinity in mice. MAbs 4:101-109.

Dong JQ, Salinger DH, Endres CJ, Gibbs JP, Hsu CP, Stouch BJ, Hurh E, and Gibbs MA (2011) Quantitative Prediction of Human Pharmacokinetics for Monoclonal Antibodies Retrospective Analysis of Monkey as a Single Species for First-in-Human Prediction. Clinical Pharmacokinetics 50:131-142.

Falck D, Thomann M, Lechmann M, Koeleman CAM, Malik S, Jany C, Wuhrer M, and Reusch D (2021) Glycoform-resolved pharmacokinetic studies in a rat model employing glycoengineered variants of a therapeutic monoclonal antibody. MAbs 13:1865596. 
Fan J, Zhuang X, Yang X, Xu Y, Zhou Z, Pan L, and Chen S (2021) A multivalent biparatopic EGFRtargeting nanobody drug conjugate displays potent anticancer activity in solid tumor models. Signal Transduct Target Ther 6:320.

Ferl GZ, Theil FP, and Wong H (2016) Physiologically based pharmacokinetic models of small molecules and therapeutic antibodies: a mini-review on fundamental concepts and applications. Biopharm Drug Dispos 37:75-92.

Ferl GZ, Wu AM, and DiStefano JJ, 3rd (2005) A predictive model of therapeutic monoclonal antibody dynamics and regulation by the neonatal Fc receptor (FcRn). Ann Biomed Eng 33:1640-1652.

Friden PM, Walus LR, Musso GF, Taylor MA, Malfroy B, and Starzyk RM (1991) Anti-transferrin receptor antibody and antibody-drug conjugates cross the blood-brain barrier. Proc Natl Acad Sci U S A 88:4771-4775.

Fujimori K, Covell DG, Fletcher JE, and Weinstein JN (1990) A modeling analysis of monoclonal antibody percolation through tumors: a binding-site barrier. J Nucl Med 31:1191-1198.

Gadkar K, Yadav DB, Zuchero JY, Couch JA, Kanodia J, Kenrick MK, Atwal JK, Dennis MS, Prabhu S, Watts RJ, Joseph SB, and Ramanujan S (2016) Mathematical PKPD and safety model of bispecific TfR/BACE1 antibodies for the optimization of antibody uptake in brain. Eur $J$ Pharm Biopharm 101:53-61.

Gaohua L, Wedagedera J, Small BG, Almond L, Romero K, Hermann D, Hanna D, Jamei M, and Gardner I (2015) Development of a Multicompartment Permeability-Limited Lung PBPK Model and Its Application in Predicting Pulmonary Pharmacokinetics of Antituberculosis Drugs. CPT Pharmacometrics Syst Pharmacol 4:605-613.

Garg A and Balthasar JP (2007) Physiologically-based pharmacokinetic (PBPK) model to predict lgG tissue kinetics in wild-type and FcRn-knockout mice. J Pharmacokinet Pharmacodyn 34:687709.

Germovsek E, Cheng M, and Giragossian C (2021) Allometric scaling of therapeutic monoclonal antibodies in preclinical and clinical settings. MAbs 13:1964935.

Gibbs JP, Yuraszeck T, Biesdorf C, Xu Y, and Kasichayanula S (2020) Informing Development of Bispecific Antibodies Using Physiologically Based Pharmacokinetic-Pharmacodynamic Models: Current Capabilities and Future Opportunities. Journal of Clinical Pharmacology 60:S132-S146.

Gibiansky L and Frey N (2012) Linking interleukin-6 receptor blockade with tocilizumab and its hematological effects using a modeling approach. J Pharmacokinet Pharmacodyn 39:5-16.

Gibiansky $L$ and Gibiansky E (2014) Target-mediated drug disposition model and its approximations for antibody-drug conjugates. J Pharmacokinet Pharmacodyn 41:35-47.

Gibiansky L, Gibiansky E, Kakkar T, and Ma P (2008) Approximations of the target-mediated drug disposition model and identifiability of model parameters. J Pharmacokinet Pharmacodyn 35:573-591.

Gill KL, Gardner I, Li L, and Jamei M (2016) A Bottom-Up Whole-Body Physiologically Based Pharmacokinetic Model to Mechanistically Predict Tissue Distribution and the Rate of Subcutaneous Absorption of Therapeutic Proteins. AAPS J 18:156-170.

Glassman PM and Balthasar JP (2016a) Application of a catenary PBPK model to predict the disposition of "catch and release" anti-PCSK9 antibodies. Int J Pharm 505:69-78.

Glassman PM and Balthasar JP (2016b) Physiologically-based pharmacokinetic modeling to predict the clinical pharmacokinetics of monoclonal antibodies. J Pharmacokinet Pharmacodyn 43:427-446.

Glassman PM and Balthasar JP (2019) Physiologically-based modeling of monoclonal antibody pharmacokinetics in drug discovery and development. Drug Metab Pharmacokinet 34:3-13.

Glassman PM, Chen Y, and Balthasar JP (2015) Scale-up of a physiologically-based pharmacokinetic model to predict the disposition of monoclonal antibodies in monkeys. J Pharmacokinet Pharmacodyn 42:527-540.

Goodall LJ, Ovecka M, Rycroft D, Friel SL, Sanderson A, Mistry P, Davies ML, and Stoop AA (2015) Pharmacokinetic and Pharmacodynamic Characterisation of an Anti-Mouse TNF Receptor 1 Domain Antibody Formatted for In Vivo Half-Life Extension. PLoS One 10:e0137065. 
Grotte G (1956) Passage of dextran molecules across the blood-lymph barrier. Acta Chir Scand Suppl 211:1-84.

Haraldsson B, Nystrom J, and Deen WM (2008) Properties of the glomerular barrier and mechanisms of proteinuria. Physiol Rev 88:451-487.

Hay M, Thomas DW, Craighead JL, Economides C, and Rosenthal J (2014) Clinical development success rates for investigational drugs. Nat Biotechnol 32:40-51.

Hu S and D'Argenio DZ (2020) Predicting monoclonal antibody pharmacokinetics following subcutaneous administration via whole-body physiologically-based modeling. J Pharmacokinet Pharmacodyn 47:385-409.

Ibrahim R, Nitsche JM, and Kasting GB (2012) Dermal clearance model for epidermal bioavailability calculations. J Pharm Sci 101:2094-2108.

Jones HM, Tolsma J, Zhang Z, Jasper P, Luo H, Weber GL, Wright K, Bard J, Bell R, Messing D, Kelleher K, Piche-Nicholas N, and Webster R (2020) A Physiologically-Based Pharmacokinetic Model for the Prediction of "Half-Life Extension" and "Catch and Release" Monoclonal Antibody Pharmacokinetics. CPT Pharmacometrics Syst Pharmacol 9:534-541.

Jones HM, Zhang Z, Jasper P, Luo H, Avery LB, King LE, Neubert H, Barton HA, Betts AM, and Webster R (2019) A Physiologically-Based Pharmacokinetic Model for the Prediction of Monoclonal Antibody Pharmacokinetics From In Vitro Data. CPT Pharmacometrics Syst Pharmacol 8:738-747.

Kagan $L$ (2014) Pharmacokinetic modeling of the subcutaneous absorption of therapeutic proteins. Drug Metab Dispos 42:1890-1905.

Kagan L, Gershkovich P, Mendelman A, Amsili S, Ezov N, and Hoffman A (2007) The role of the lymphatic system in subcutaneous absorption of macromolecules in the rat model. Eur $J$ Pharm Biopharm 67:759-765.

Kanda Y, Yamada T, Mori K, Okazaki A, Inoue M, Kitajima-Miyama K, Kuni-Kamochi R, Nakano R, Yano K, Kakita S, Shitara K, and Satoh M (2007) Comparison of biological activity among nonfucosylated therapeutic IgG1 antibodies with three different $\mathrm{N}$-linked Fc oligosaccharides: the high-mannose, hybrid, and complex types. Glycobiology 17:104-118.

Kang JC, Sun W, Khare P, Karimi M, Wang X, Shen Y, Ober RJ, and Ward ES (2019) Engineering a HER2-specific antibody-drug conjugate to increase lysosomal delivery and therapeutic efficacy. Nat Biotechnol 37:523-526.

Kanodia JS, Gadkar K, Bumbaca D, Zhang Y, Tong RK, Luk W, Hoyte K, Lu Y, Wildsmith KR, Couch JA, Watts RJ, Dennis MS, Ernst JA, Scearce-Levie K, Atwal JK, Ramanujan S, and Joseph S (2016) Prospective Design of Anti-Transferrin Receptor Bispecific Antibodies for Optimal Delivery into the Human Brain. CPT Pharmacometrics Syst Pharmacol 5:283-291.

Kasturirangan S, Rainey GJ, Xu L, Wang X, Portnoff A, Chen T, Fazenbaker C, Zhong H, Bee J, Zeng Z, Jenne C, Wu H, and Gao C (2017) Targeted Fcgamma Receptor (FcgammaR)-mediated Clearance by a Biparatopic Bispecific Antibody. J Biol Chem 292:4361-4370.

Kathman S, Jr., Thway TM, Zhou L, Lee S, Yu S, Ma M, Chirmule N, and Jawa V (2016) Utility of a Bayesian Mathematical Model to Predict the Impact of Immunogenicity on Pharmacokinetics of Therapeutic Proteins. AAPS J 18:424-431.

Khot A, Tibbitts J, Rock D, and Shah DK (2017) Development of a Translational Physiologically Based Pharmacokinetic Model for Antibody-Drug Conjugates: a Case Study with T-DM1. AAPS J 19:1715-1734.

Kola I and Landis J (2004) Can the pharmaceutical industry reduce attrition rates? Nat Rev Drug Discov 3:711-715.

Kuang B, King L, and Wang HF (2010) Therapeutic monoclonal antibody concentration monitoring: free or total? Bioanalysis 2:1125-1140.

Lagasse HA, Alexaki A, Simhadri VL, Katagiri NH, Jankowski W, Sauna ZE, and Kimchi-Sarfaty C (2017) Recent advances in (therapeutic protein) drug development. F1000Res 6:113. 
Latvala S, Jacobsen B, Otteneder MB, Herrmann A, and Kronenberg S (2017) Distribution of FcRn Across Species and Tissues. J Histochem Cytochem 65:321-333.

Lavezzi SM, Mezzalana E, Zamuner S, De Nicolao G, Ma P, and Simeoni M (2018) MPBPK-TMDD models for mAbs: alternative models, comparison, and identifiability issues. $J$ Pharmacokinet Pharmacodyn 45:787-802.

Levy G (1994) Pharmacologic target-mediated drug disposition. Clin Pharmacol Ther 56:248-252.

Li JY, Perry SR, Muniz-Medina V, Wang X, Wetzel LK, Rebelatto MC, Hinrichs MJ, Bezabeh BZ, Fleming RL, Dimasi N, Feng H, Toader D, Yuan AQ, Xu L, Lin J, Gao C, Wu H, Dixit R, Osbourn JK, and Coats SR (2016) A Biparatopic HER2-Targeting Antibody-Drug Conjugate Induces Tumor Regression in Primary Models Refractory to or Ineligible for HER2-Targeted Therapy. Cancer Cell 29:117-129.

Li L, Gardner I, Rose R, and Jamei M (2014) Incorporating Target Shedding Into a Minimal PBPKTMDD Model for Monoclonal Antibodies. CPT Pharmacometrics Syst Pharmacol 3:e96.

$\mathrm{Li}$ T and Balthasar JP (2018) FcRn Expression in Wildtype Mice, Transgenic Mice, and in Human Tissues. Biomolecules 8.

Li T and Balthasar JP (2019) Application of Physiologically Based Pharmacokinetic Modeling to Predict the Effects of FcRn Inhibitors in Mice, Rats, and Monkeys. J Pharm Sci 108:701-713.

Li Z and Shah DK (2019) Two-pore physiologically based pharmacokinetic model with de novo derived parameters for predicting plasma PK of different size protein therapeutics. J Pharmacokinet Pharmacodyn 46:305-318.

Li Z, Yu X, Li Y, Verma A, Chang HP, and Shah DK (2021) A Two-Pore Physiologically Based Pharmacokinetic Model to Predict Subcutaneously Administered Different-Size Antibody/Antibody Fragments. AAPS J 23:62.

Liang W, Pan HW, Vllasaliu D, and Lam JKW (2020) Pulmonary Delivery of Biological Drugs. Pharmaceutics 12.

Lobo ED, Hansen RJ, and Balthasar JP (2004) Antibody pharmacokinetics and pharmacodynamics. $J$ Pharm Sci 93:2645-2668.

Maass KF, Kulkarni C, Betts AM, and Wittrup KD (2016) Determination of Cellular Processing Rates for a Trastuzumab-Maytansinoid Antibody-Drug Conjugate (ADC) Highlights Key Parameters for ADC Design. AAPS J 18:635-646.

Mach H, Gregory SM, Mackiewicz A, Mittal S, Lalloo A, Kirchmeier M, and Shameem M (2011) Electrostatic interactions of monoclonal antibodies with subcutaneous tissue. Ther Deliv 2:727736.

Mager DE and Jusko WJ (2001) General pharmacokinetic model for drugs exhibiting target-mediated drug disposition. J Pharmacokinet Pharmacodyn 28:507-532.

Mager DE and Krzyzanski W (2005) Quasi-equilibrium pharmacokinetic model for drugs exhibiting target-mediated drug disposition. Pharm Res 22:1589-1596.

Malik PRV and Edginton AN (2020) Integration of Ontogeny Into a Physiologically Based Pharmacokinetic Model for Monoclonal Antibodies in Premature Infants. J Clin Pharmacol 60:466-476.

Malik PRV, Hamadeh A, Phipps C, and Edginton AN (2017) Population PBPK modelling of trastuzumab: a framework for quantifying and predicting inter-individual variability. J Pharmacokinet Pharmacodyn 44:277-290.

Mandikian D, Figueroa I, Oldendorp A, Rafidi H, Ulufatu S, Schweiger MG, Couch JA, Dybdal N, Joseph SB, Prabhu S, Ferl GZ, and Boswell CA (2018) Tissue Physiology of Cynomolgus Monkeys: Cross-Species Comparison and Implications for Translational Pharmacology. AAPS J 20:107.

Marathe A, Krzyzanski W, and Mager DE (2009) Numerical validation and properties of a rapid binding approximation of a target-mediated drug disposition pharmacokinetic model. $J$ Pharmacokinet Pharmacodyn 36:199-219. 
McDonald TA, Zepeda ML, Tomlinson MJ, Bee WH, and Ivens IA (2010) Subcutaneous administration of biotherapeutics: current experience in animal models. Curr Opin Mol Ther 12:461-470.

Meibohm B and Zhou H (2012) Characterizing the impact of renal impairment on the clinical pharmacology of biologics. J Clin Pharmacol 52:54S-62S.

Meyer S, Nederend M, Jansen JH, Reiding KR, Jacobino SR, Meeldijk J, Bovenschen N, Wuhrer M, Valerius T, Ubink R, Boross P, Rouwendal G, and Leusen JH (2016) Improved in vivo antitumor effects of $\lg \mathrm{A}-\mathrm{Her} 2$ antibodies through half-life extension and serum exposure enhancement by FcRn targeting. MAbs 8:87-98.

Montoyo HP, Vaccaro C, Hafner M, Ober RJ, Mueller W, and Ward ES (2009) Conditional deletion of the $\mathrm{MHC}$ class I-related receptor FcRn reveals the sites of IgG homeostasis in mice. Proc Natl Acad Sci U S A 106:2788-2793.

Morgan P, Van Der Graaf PH, Arrowsmith J, Feltner DE, Drummond KS, Wegner CD, and Street SD (2012) Can the flow of medicines be improved? Fundamental pharmacokinetic and pharmacological principles toward improving Phase II survival. Drug Discov Today 17:419-424.

Mortensen DL, Prabhu S, Stefanich EG, Kadkhodayan-Fischer S, Gelzleichter TR, Baker D, Jiang J, Wallace K, lyer S, Fielder PJ, and Putnam WS (2012) Effect of antigen binding affinity and effector function on the pharmacokinetics and pharmacodynamics of anti-lgE monoclonal antibodies. MAbs 4:724-731.

Mullard A (2021) FDA approves 100th monoclonal antibody product. Nat Rev Drug Discov 20:491-495.

$\mathrm{Ng} \mathrm{CM}$, Bruno R, Combs D, and Davies B (2005) Population pharmacokinetics of rituximab (anti-CD20 monoclonal antibody) in rheumatoid arthritis patients during a phase II clinical trial. J Clin Pharmacol 45:792-801.

Niederalt C, Kuepfer L, Solodenko J, Eissing T, Siegmund HU, Block M, Willmann S, and Lippert J (2018) A generic whole body physiologically based pharmacokinetic model for therapeutic proteins in PK-Sim. J Pharmacokinet Pharmacodyn 45:235-257.

Niewoehner J, Bohrmann B, Collin L, Urich E, Sade H, Maier P, Rueger P, Stracke JO, Lau W, Tissot AC, Loetscher H, Ghosh A, and Freskgard PO (2014) Increased brain penetration and potency of a therapeutic antibody using a monovalent molecular shuttle. Neuron 81:49-60.

Ober RJ, Radu CG, Ghetie V, and Ward ES (2001) Differences in promiscuity for antibody-FcRn interactions across species: implications for therapeutic antibodies. Int Immunol 13:1551-1559.

Offman E and Edginton AN (2015) A PBPK workflow for first-in-human dose selection of a subcutaneously administered pegylated peptide. J Pharmacokinet Pharmacodyn 42:135-150.

Offman E, Phipps C, and Edginton AN (2016) Population physiologically-based pharmacokinetic model incorporating lymphatic uptake for a subcutaneously administered pegylated peptide. In Silico Pharmacol 4:3.

Pan X, Stader F, Abduljalil K, Gill KL, Johnson TN, Gardner I, and Jamei M (2020) Development and Application of a Physiologically-Based Pharmacokinetic Model to Predict the Pharmacokinetics of Therapeutic Proteins from Full-term Neonates to Adolescents. AAPS J 22:76.

Patton JS, Brain JD, Davies LA, Fiegel J, Gumbleton M, Kim KJ, Sakagami M, Vanbever R, and Ehrhardt C (2010) The particle has landed--characterizing the fate of inhaled pharmaceuticals. $J$ Aerosol Med Pulm Drug Deliv 23 Suppl 2:S71-87.

Patton JS and Byron PR (2007) Inhaling medicines: delivering drugs to the body through the lungs. Nat Rev Drug Discov 6:67-74.

Peletier LA and Gabrielsson J (2018) New Equilibrium Models of Drug-Receptor Interactions Derived from Target-Mediated Drug Disposition. AAPS J 20:69.

Perez Ruixo JJ, Ma P, and Chow AT (2013) The utility of modeling and simulation approaches to evaluate immunogenicity effect on the therapeutic protein pharmacokinetics. AAPS J 15:172182.

Perez VL, Saeed AM, Tan Y, Urbieta M, and Cruz-Guilloty F (2013) The eye: A window to the soul of the immune system. J Autoimmun 45:7-14. 
Porter CJ and Charman SA (2000) Lymphatic transport of proteins after subcutaneous administration. $J$ Pharm Sci 89:297-310.

Porter CJ, Edwards GA, and Charman SA (2001) Lymphatic transport of proteins after s.c. injection: implications of animal model selection. Adv Drug Deliv Rev 50:157-171.

Rabkin R and Dahl DC (1993) Renal uptake and disposal of proteins and peptides, in: Biological Barriers to Protein Delivery, pp 299-338, Springer.

Rafidi H, Estevez A, Ferl GZ, Mandikian D, Stainton S, Sermeno L, Williams SP, Kamath AV, Koerber JT, and Boswell CA (2021) Imaging Reveals Importance of Shape and Flexibility for Glomerular Filtration of Biologics. Mol Cancer Ther.

Reddy ST, Berk DA, Jain RK, and Swartz MA (2006) A sensitive in vivo model for quantifying interstitial convective transport of injected macromolecules and nanoparticles. J Appl Physiol (1985) 101:1162-1169.

Richter WF, Christianson GJ, Frances N, Grimm HP, Proetzel G, and Roopenian DC (2018) Hematopoietic cells as site of first-pass catabolism after subcutaneous dosing and contributors to systemic clearance of a monoclonal antibody in mice. MAbs 10:803-813.

Richter WF and Jacobsen B (2014) Subcutaneous absorption of biotherapeutics: knowns and unknowns. Drug Metab Dispos 42:1881-1889.

Rippe B and Haraldsson B (1987) Fluid and protein fluxes across small and large pores in the microvasculature. Application of two-pore equations. Acta Physiol Scand 131:411-428.

Rippe B and Haraldsson B (1994) Transport of macromolecules across microvascular walls: the twopore theory. Physiol Rev 74:163-219.

Sanches M, D'Angelo I, Jaramillo M, Baardsnes J, Zwaagstra J, Schrag J, Schoenhofen I, Acchione M, Lawn S, Wickman G, Weisser N, Poon DKY, Ng G, and Dixit S (2020) AlbuCORE: an albuminbased molecular scaffold for multivalent biologics design. MAbs 12:1802188.

Sanchez-Felix M, Burke M, Chen HH, Patterson C, and Mittal S (2020) Predicting bioavailability of monoclonal antibodies after subcutaneous administration: Open innovation challenge. Adv Drug Deliv Rev 167:66-77.

Schmidt MM and Wittrup KD (2009) A modeling analysis of the effects of molecular size and binding affinity on tumor targeting. Mol Cancer Ther 8:2861-2871.

Sepp A, Berges A, Sanderson A, and Meno-Tetang G (2015) Development of a physiologically based pharmacokinetic model for a domain antibody in mice using the two-pore theory. $J$ Pharmacokinet Pharmacodyn 42:97-109.

Sepp A, Bergstrom M, and Davies M (2020) Cross-species/cross-modality physiologically based pharmacokinetics for biologics: 89Zr-labelled albumin-binding domain antibody GSK3128349 in humans. MAbs 12:1832861.

Sepp A, Meno-Tetang G, Weber A, Sanderson A, Schon O, and Berges A (2019) Computer-assembled cross-species/cross-modalities two-pore physiologically based pharmacokinetic model for biologics in mice and rats. J Pharmacokinet Pharmacodyn 46:339-359.

Shah DK (2015) Pharmacokinetic and pharmacodynamic considerations for the next generation protein therapeutics. J Pharmacokinet Pharmacodyn 42:553-571.

Shah DK and Betts AM (2012) Towards a platform PBPK model to characterize the plasma and tissue disposition of monoclonal antibodies in preclinical species and human. J Pharmacokinet Pharmacodyn 39:67-86.

Shah DK, Shin BS, Veith J, Toth K, Bernacki RJ, and Balthasar JP (2009) Use of an anti-vascular endothelial growth factor antibody in a pharmacokinetic strategy to increase the efficacy of intraperitoneal chemotherapy. J Pharmacol Exp Ther 329:580-591.

Singh AP, Seigel GM, Guo L, Verma A, Wong GG, Cheng HP, and Shah DK (2020) Evolution of the Systems Pharmacokinetics-Pharmacodynamics Model for Antibody-Drug Conjugates to Characterize Tumor Heterogeneity and In Vivo Bystander Effect. J Pharmacol Exp Ther 374:184-199. 
Singh AP and Shah DK (2017a) Application of a PK-PD Modeling and Simulation-Based Strategy for Clinical Translation of Antibody-Drug Conjugates: a Case Study with Trastuzumab Emtansine (T-DM1). AAPS J 19:1054-1070.

Singh AP and Shah DK (2017b) Measurement and Mathematical Characterization of Cell-Level Pharmacokinetics of Antibody-Drug Conjugates: A Case Study with Trastuzumab-vc-MMAE. Drug Metab Dispos 45:1120-1132.

Stork R, Muller D, and Kontermann RE (2007) A novel tri-functional antibody fusion protein with improved pharmacokinetic properties generated by fusing a bispecific single-chain diabody with an albumin-binding domain from streptococcal protein G. Protein Eng Des Sel 20:569-576.

Thurber GM, Schmidt MM, and Wittrup KD (2008) Antibody tumor penetration: transport opposed by systemic and antigen-mediated clearance. Adv Drug Deliv Rev 60:1421-1434.

Thurber GM and Wittrup DK (2012) A mechanistic compartmental model for total antibody uptake in tumors. J Theor Biol 314:57-68.

Uchida J, Hamaguchi Y, Oliver JA, Ravetch JV, Poe JC, Haas KM, and Tedder TF (2004) The innate mononuclear phagocyte network depletes $B$ lymphocytes through Fc receptor-dependent mechanisms during anti-CD20 antibody immunotherapy. J Exp Med 199:1659-1669.

Urquhart L (2021) Top companies and drugs by sales in 2020. Nat Rev Drug Discov 20:253.

Urva SR, Yang VC, and Balthasar JP (2010) Physiologically based pharmacokinetic model for T84.66: a monoclonal anti-CEA antibody. J Pharm Sci 99:1582-1600.

Vidarsson G, Stemerding AM, Stapleton NM, Spliethoff SE, Janssen H, Rebers FE, de Haas M, and van de Winkel JG (2006) FcRn: an IgG receptor on phagocytes with a novel role in phagocytosis. Blood 108:3573-3579.

Vugmeyster Y, Xu X, Theil FP, Khawli LA, and Leach MW (2012) Pharmacokinetics and toxicology of therapeutic proteins: Advances and challenges. World J Biol Chem 3:73-92.

Wang W, Wang EQ, and Balthasar JP (2008) Monoclonal antibody pharmacokinetics and pharmacodynamics. Clin Pharmacol Ther 84:548-558.

Wienkers LC and Heath TG (2005) Predicting in vivo drug interactions from in vitro drug discovery data. Nat Rev Drug Discov 4:825-833.

Wright A, Sato Y, Okada T, Chang K, Endo T, and Morrison S (2000) In vivo trafficking and catabolism of IgG1 antibodies with Fc associated carbohydrates of differing structure. Glycobiology 10:1347-1355.

Yang D, Giragossian C, Castellano S, Lasaro M, Xiao H, Saraf H, Hess Kenny C, Rybina I, Huang ZF, Ahlberg J, Bigwarfe T, Myzithras M, Waltz E, Roberts S, Kroe-Barrett R, and Singh S (2017) Maximizing in vivo target clearance by design of $\mathrm{pH}$-dependent target binding antibodies with altered affinity to FcRn. MAbs 9:1105-1117.

Yu M, Brown D, Reed C, Chung S, Lutman J, Stefanich E, Wong A, Stephan JP, and Bayer R (2012) Production, characterization, and pharmacokinetic properties of antibodies with $\mathrm{N}$-linked mannose-5 glycans. MAbs 4:475-487.

Yu YJ, Zhang Y, Kenrick M, Hoyte K, Luk W, Lu Y, Atwal J, Elliott JM, Prabhu S, Watts RJ, and Dennis MS (2011) Boosting brain uptake of a therapeutic antibody by reducing its affinity for a transcytosis target. Sci Transl Med 3:84ra44.

Yu YR, O'Koren EG, Hotten DF, Kan MJ, Kopin D, Nelson ER, Que L, and Gunn MD (2016) A Protocol for the Comprehensive Flow Cytometric Analysis of Immune Cells in Normal and Inflamed Murine Non-Lymphoid Tissues. PLoS One 11:e0150606.

Zhao J, Cao YG, and Jusko WJ (2015) Across-Species Scaling of Monoclonal Antibody Pharmacokinetics Using a Minimal PBPK Model. Pharmaceutical Research 32:3269-3281.

Zhao L, Ji P, Li Z, Roy P, and Sahajwalla CG (2013) The antibody drug absorption following subcutaneous or intramuscular administration and its mathematical description by coupling physiologically based absorption process with the conventional compartment pharmacokinetic model. J Clin Pharmacol 53:314-325. 
Zheng Y, Tesar DB, Benincosa L, Birnbock H, Boswell CA, Bumbaca D, Cowan KJ, Danilenko DM, Daugherty AL, Fielder PJ, Grimm HP, Joshi A, Justies N, Kolaitis G, Lewin-Koh N, Li J, McVay S, O'Mahony J, Otteneder M, Pantze M, Putnam WS, Qiu ZJ, Ruppel J, Singer T, Stauch O, Theil FP, Visich J, Yang J, Ying Y, Khawli LA, and Richter WF (2012) Minipig as a potential translatable model for monoclonal antibody pharmacokinetics after intravenous and subcutaneous administration. MAbs 4:243-255. 
Figure 1. Schematic of ADME models for TPs. (A) Structure of a whole-body PBPK model for TPs' disposition (adapted from (Shah and Betts, 2012)). Organs are represented by rectangular compartments connected via blood flows (solid arrows) and lymphatic flows (dashed arrows). S.M. int refers to small intestine, and L.G. int refers to large intestine. Organ-specific distribution or elimination mechanisms will be elaborated below for tumor, brain, eye, kidney, and skin. (B) Diagram of tissuelevel models that characterize distribution of TPs for a typical organ (adapted from (Sepp et al., 2019)), based on one-pore (left) or two-pore (right) theories. A tissue is divided into vascular, endosomal, and interstitial spaces. Diffusion is denoted by solid arrows, and convection by dashed arrows. Specially, curved arrows stand for the isogravimetric flow. (C) Representation of the Krogh cylinder tumor model (adapted from (Cilliers et al., 2016)). The area in red refers to tumoral vasculature, from where TPs can escape via diffusion. Transport of TPs can also be driven by surface uptake from an adjacent organ. (D) Structure of the brain PBPK model. Brain is divided into vascular, BCSFB, BBB, CSF, and parenchymal compartments. (E) Structure of the ocular PBPK model. Regions in the eye include cornea, ICB, lens, retina, choroid, sclera, aqueous humor, and vitreous humor. Black solid arrows represent blood flows, green dashed arrows represent convective flows, and red double-headed arrows represent diffusion processes. (F) Representation of endosomal models that characterize FcRn interaction with IgGs (adapted from (Chen and Balthasar, 2012)). Figure on the left hand side assumes equilibrium binding between IgGs and FcRn. Figure on the right hand side adopts a catenary model, where endosomal sub-compartments have $\mathrm{pH}$ ranging from 7.4 to 6.0. (G) Representation of a TMDD model for a membrane-bound antigen in the tumor compartment. The free receptor has its inherent turnover rate, and is allowed to bind to TPs in the extracellular space of a solid tumor. $(\mathrm{H})$ Schematic of renal elimination of TPs (adapted from (Rabkin and Dahl, 1993)). Following glomerular filtration, TPs are internalized into tubular cells for degradation or eliminated into the urine. TPs in the postglomerular peritubular capillaries can also be endocytosed followed by intracellular degradation. (I) Structure of a SC absorption model (adapted from (Hu and D'Argenio, 2020)). 
Table 1. Summary and characteristics of various PK models for TPs.

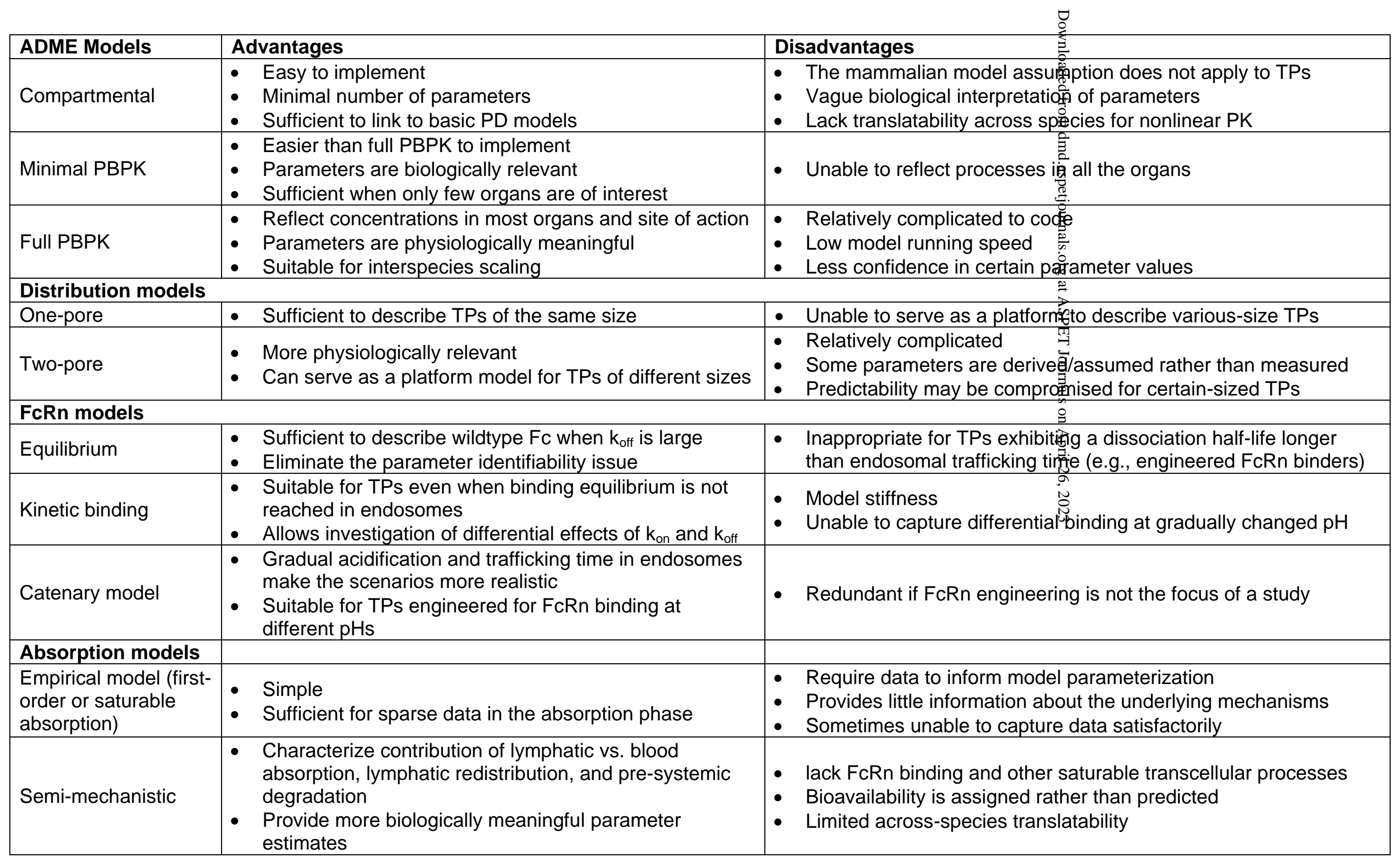


- Compatible with compartmental or mPBPK models

- Suitable in compartmental, mPBPK, and PBPK frameworks

Mechanistic

- Provide insights into various absorption mechanisms

- Have better capability of interspecies scaling

- Can guide dosing strategies

\section{일}

- Limited knowledge about the model parameterization 
Table 2. Examples of models that have been validated for cross-species or cross-population predictability of TPs' PK.

\begin{tabular}{|c|c|c|}
\hline Model reference & Model characteristics & Model description/application \\
\hline (Dong et al., 2011) & $\begin{array}{l}\text { Two-compartment model, } \\
\text { allometric scaling }\end{array}$ & $\begin{array}{l}\text { Prediction of linear plasma PK of mAbs following IV } \\
\text { and SC administration in humans based on } \\
\text { monkey PK data }\end{array}$ \\
\hline (Zhao et al., 2015) & $\begin{array}{l}\text { mPBPK, FcRn binding not } \\
\text { included }\end{array}$ & $\begin{array}{l}\text { Prediction of linear plasma PK of mAbs following IV } \\
\text { administration in mice, rats, monkeys, and humans }\end{array}$ \\
\hline $\begin{array}{l}\text { (Chen and Balthasar, 2012) } \\
\text { (Glassman et al., 2015) } \\
\text { (Glassman and Balthasar, 2016b) }\end{array}$ & $\begin{array}{l}\text { PBPK, TMDD (equilibrium } \\
\text { binding), catenary endosomal } \\
\text { model }\end{array}$ & $\begin{array}{l}\text { Prediction of nonlinear plasma PK of mAbs in the } \\
\text { presence of therapeutic targets across doses in } \\
\text { mice, monkeys, and humans }\end{array}$ \\
\hline $\begin{array}{l}\text { (Offman and Edginton, 2015) } \\
\text { (Offman et al., 2016) }\end{array}$ & PBPK, one-pore & $\begin{array}{l}\text { Prediction of SC PK of a pegylated peptide across } \\
\text { dose levels in humans based on PK data following } \\
\text { IV and SC administration in monkeys and one dose } \\
\text { level of SC administration in humans }\end{array}$ \\
\hline (Chang et al., 2019) & $\begin{array}{l}\text { PBPK, kinetic FcRn binding, } \\
\text { brain distribution submodel }\end{array}$ & $\begin{array}{l}\text { Prediction of non-targeting mAb disposition in } \\
\text { whole brain and CSF in mice, rats, monkeys, and } \\
\text { humans }\end{array}$ \\
\hline $\begin{array}{l}\text { (Shah and Betts, 2012) } \\
\text { (Chang et al., 2021a) }\end{array}$ & $\begin{array}{l}\text { PBPK, kinetic FcRn binding, } \\
\text { age-dependent physiological } \\
\text { parameter values }\end{array}$ & $\begin{array}{l}\text { Prediction of plasma PK of mAbs following IV } \\
\text { administration in mice, rats, monkeys, human } \\
\text { adults, and pediatric patients }\end{array}$ \\
\hline (Pan et al., 2020) & $\begin{array}{l}\text { PBPK, TMDD, two-pore, semi- } \\
\text { mechanistic or first-order } \\
\text { absorption model, age- } \\
\text { dependent physiological } \\
\text { parameter values }\end{array}$ & $\begin{array}{l}\text { Prediction of plasma PK of different-size TPS } \\
\text { following IV or SC administration in full-term } \\
\text { neonates, infants, children, adolescents, and adults }\end{array}$ \\
\hline (Khot et al., 2017) & $\begin{array}{l}\text { PBPK, tumor disposition } \\
\text { model, allometric scaling }\end{array}$ & $\begin{array}{l}\text { Prediction of plasma PK of different analytes of an } \\
\text { ADC based on rat PK data }\end{array}$ \\
\hline
\end{tabular}


DMD Fast Forward. Published on February 23, 2022 as DOI: 10.1124/dmd.121.000460

This article has not been copyedited and formatted. The final version may differ from this version.

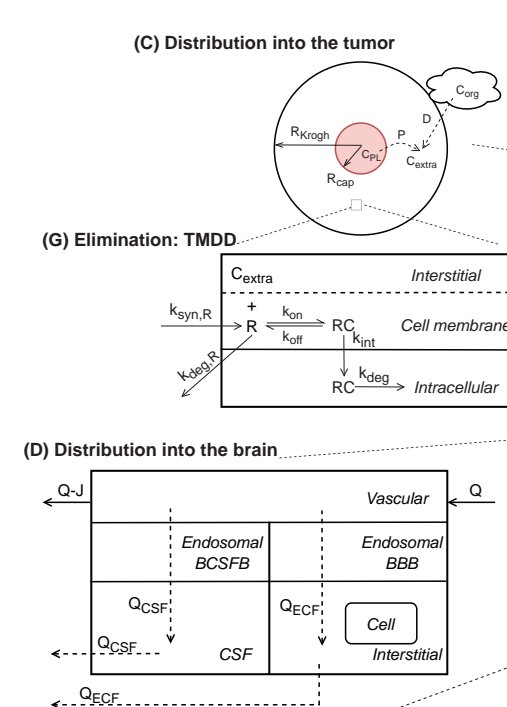

(A) PBPK structure

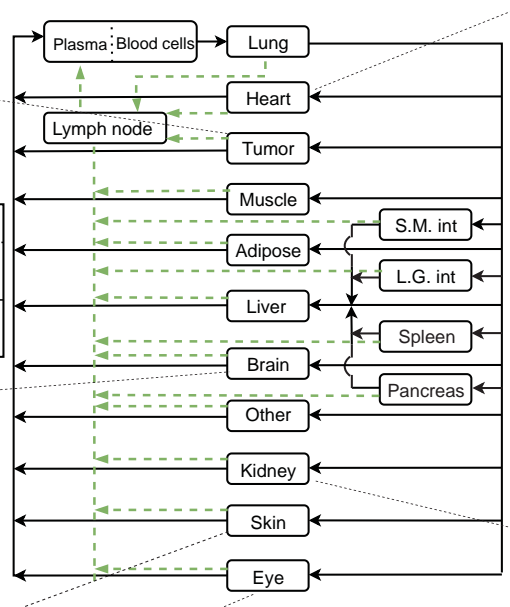

(E) Distribution into the eye

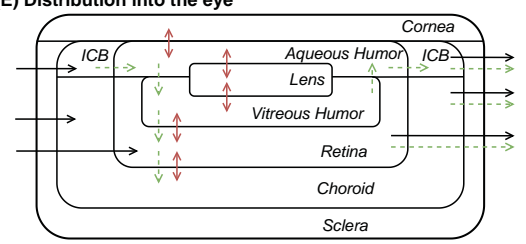

(B) Distribution into typical tissues: one-pore vs. two-pore

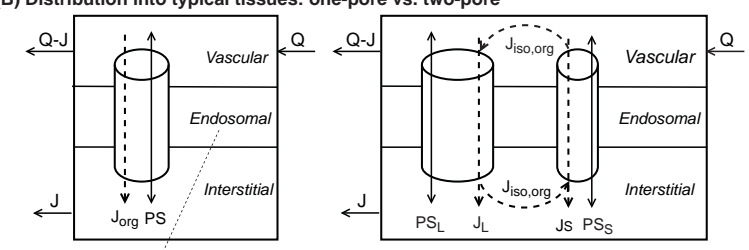

(F) Elimination: FcRn-mediated salvage (equilibrium binding vs. catenary model)
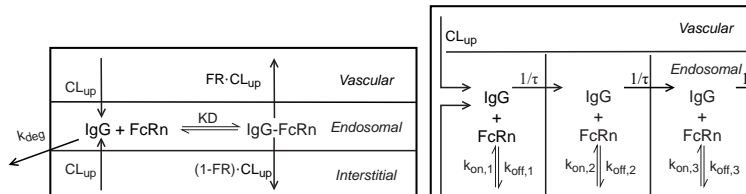
${ }_{1 / \tau} \quad 1 / \tau \mid$ Endosomal $_{1 / \tau}$ $\longrightarrow \operatorname{lgG} \stackrel{1 / \tau}{\longrightarrow} \operatorname{lgG} \stackrel{1 / \tau}{\longrightarrow} \stackrel{\text { Endosomal } 1 / \tau}{\longrightarrow} \stackrel{\lg G}{ } \stackrel{1 / \tau}{\longrightarrow}$

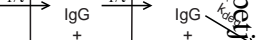

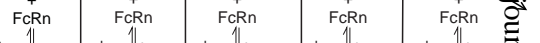

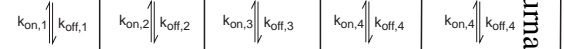

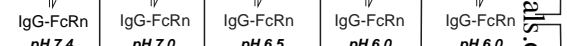

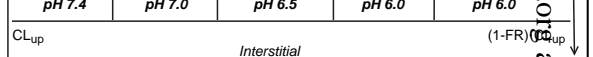
(H) Elimination: renal filtration and catabolism $\stackrel{2}{2}$

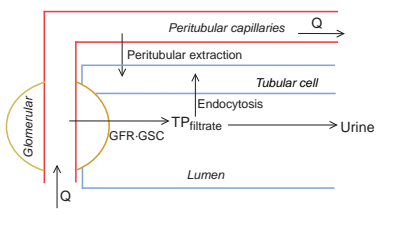

